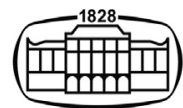

AKADÉMIAI KIADÓ

Journal of Behavioral Addictions

10 (2021) 4, 1015-1035

DOI:

$10.1556 / 2006.2021 .00070$

(c) 2021 The Author(s)

\section{FULL-LENGTH REPORT}

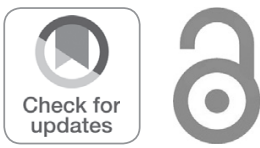

\title{
Hands-off: Feasibility and preliminary results of a two-armed randomized controlled trial of a web-based self-help tool to reduce problematic pornography use
}

\section{BEÁTA BÖTHE $^{1,2 *}$ •, CHRISTIAN BAUMGARTNER ${ }^{3}$, , MICHAEL P. SCHAUB ${ }^{3} \odot$, ZSOLT DEMETROVICS $^{4,2}$ ZCI $^{\circ}$ and GÁBOR OROSZ ${ }^{5}$}

\author{
${ }^{1}$ Département de Psychologie, Université de Montréal, Montréal, Canada \\ ${ }^{2}$ Institute of Psychology, ELTE Eötvös Loránd University, Budapest, Hungary \\ ${ }^{3}$ Swiss Research Institute for Public Health and Addiction ISGF, Associated to the University of \\ Zurich, Zurich, Switzerland \\ ${ }^{4}$ Centre of Excellence in Responsible Gaming, University of Gibraltar, Gibraltar, Gibraltar \\ ${ }^{5}$ Université d'Artois, Université de Lille, Université Littoral Côte d'Opale, ULR 7369 - URePSSS - \\ Unité de Recherche Pluridisciplinaire Sport Santé Société, Atelier Sherpas, F-62800, Liévin, France
}

Received: July 1, 2021 - Revised manuscript received: September 14, 2021 - Accepted: October 4, 2021

Published online: October 29, 2021
*Corresponding author. Tel.: +514 343-6111 ext. 37428.

E-mail: beata.bothe@umontreal.ca; beabothe@gmail.com

\begin{abstract}
Background and Aims: Despite problematic pornography use (PPU) being prevalent, no previous study has examined the effectiveness of evidence-based interventions for PPU, using rigorous methods. Using a two-armed randomized controlled trial study design, we examined the feasibility and initial effectiveness of a six-week online PPU intervention. Methods: We recruited 264 participants (3.8\% women, $\left.M_{\text {age }}=33.2, S D=10.6\right)$ who were randomized and assigned to either the self-help intervention $(n=$ $123)$ or waitlist control condition $(n=141)$, and completed self-report questionnaires at baseline and after the end of the intervention (six-week follow-up). Multivariable linear regression models were generated and tested on a complete case basis to investigate possible treatment effects. Participants provided quantitative and qualitative feedback regarding the intervention's content and appearance. Results: Participants evaluated all modules positively in the intervention in general. There were differential dropout rates ( $89.4 \%$ in intervention vs. $44.7 \%$ in control group) with an overall follow-up rate of $34.5 \%$. The intervention group reported significantly lower levels of PPU $(P<0.001, d=1.32)$ at the six-week follow-up. Moreover, they reported lower pornography use frequency $(P<0.001, d=1.65)$, self-perceived pornography addiction $(P=0.01, d=0.85)$, pornography craving $(P=0.02, d=0.40)$, and higher pornography avoidance self-efficacy $(P=0.001, d=0.87)$ at the six-week follow-up. Discussion and Conclusions: The present study was only a first step in rigorous treatment studies for PPU, but the findings are promising and suggest that online interventions for PPU might help reduce PPU in some cases, even without the guidance of therapists, by reducing treatment barriers.
\end{abstract}

\section{KEYWORDS}

cognitive-behavioral therapy, compulsive sexual behavior, feasibility, online intervention, problematic pornography use

\section{INTRODUCTION}

Pornography use is prevalent among adolescents and adults (Böthe, Vaillancourt-Morel, et al., 2020, 2021; Grubbs et al., 2020; Wright, Herbenick, \& Paul, 2019). Findings of nationally representative studies from Australia (Rissel et al., 2017), Europe (Lewczuk, Glica, 
Nowakowska, Gola, \& Grubbs, 2020), and the US (Grubbs, Kraus, \& Perry, 2019; Herbenick et al., 2020) suggest that $84-94 \%$ of men and $54-87 \%$ of women report lifetime pornography use. Most individuals using pornography do not report distress or negative consequences deriving from their pornography use (Böthe, Tóth-Király, Potenza, Orosz, \& Demetrovics, 2020; Bőthe et al., 2021; Vaillancourt-Morel et al., 2017). Nevertheless, a small but significant ratio of people (1-3\% of women and $4-11 \%$ of men) report problematic pornography use (PPU) (Grubbs et al., 2020; Grubbs, Kraus, \& Perry, 2019; Rissel et al., 2017). PPU can be considered as a manifestation of Compulsive Sexual Behavior Disorder (CSBD) (Fernandez \& Griffiths, 2019; Kafka, 2010), now included in the $11^{\text {th }}$ revision of the International Statistical Classification of Diseases and Related Health Problems (ICD-11, World Health Organization, 2019), and might be defined as uncontrollable, persistent patterns of pornography use despite personal distress and functional impairment in different areas of life (Böthe, TóthKirály, Demetrovics, \& Orosz, 2021; Kraus et al., 2018).

Despite the prevalence of PPU and related treatmentseeking (Böthe et al., 2021; Gola, Lewczuk, \& Skorko, 2016; Kraus, Martino, \& Potenza, 2016; Lewczuk, Szmyd, Skorko, \& Gola, 2017), and proliferation of research in compulsive sexual behaviors and PPU in the past 25 years, there is still a virtual absence of rigorous, systematic, high-quality treatment-related research in PPU, resulting in the absence of effective treatment protocols for health care professionals and treatment-seeking individuals (Griffin, Way, \& Kraus, 2021; Grubbs et al., 2020). Thus, the objective of the present study was to evaluate the feasibility and report the preliminary effectiveness of a new online intervention reducing PPU, using a two-armed randomized controlled trial (RCT) study design (Böthe, Baumgartner, Schaub, Demetrovics, \& Orosz, 2020; Rounsaville, Carroll, \& Onken, 2001).

Despite the paucity of rigorous studies using gold-standard approaches (e.g., randomized controlled trials) to evaluate the effectiveness of interventions for CSBD and PPU (Efrati \& Gola, 2018; Grubbs et al., 2020), some preliminary findings of previous treatment studies are available (e.g., Dhuffar \& Griffiths, 2015; von Franqué, Klein, \& Briken, 2015; Wéry \& Billieux, 2017). However, it is important to note that most prior studies reported results of single case studies, used small, homogenous samples, and lacked proper assessment (i.e., validated measures) and control groups. The available scientific evidence regarding psychotherapeutic treatment options and their efficacy for PPU is largely limited.

Three studies reported the effectiveness of short interventions geared to reduce PPU (i.e., not compulsive sexual behaviors broadly) and included a control group (Crosby, 2011; Crosby \& Twohig, 2016; Minarcik, 2016). These studies included elements of cognitive behavior therapy (CBT) and acceptance and commitment therapy (ACT), and each reported improvement in the participants' pornography userelated symptoms. Although these studies demonstrated the potential efficacy and usefulness of CBT and ACT-based methods in reducing PPU, they were still limited by their small, homogenous samples (e.g., only men, only US samples), probably due to the interventions' offline nature (i.e., individual sessions with a therapist). Thus, rigorous, inclusive investigations are necessary to move the field forward (Griffin et al., 2021; Grubbs et al., 2020; Klein, Savaş, \& Conley, 2021).

Free, online interventions may overcome the aforementioned shortcomings, as they can reach larger and more diverse populations relatively easily, compared to traditional treatments, as was demonstrated in previous studies (Baumgartner et al., 2019; Haug, Castro, Wenger, \& Schaub, 2018; Herrero et al., 2019; Weisel et al., 2018). Online interventions may also reduce other treatment barriers that can be present in offline interventions, such as unaffordability of traditional therapies, stigma, or feelings of shame for seeking help for PPU (Dhuffar \& Griffiths, 2016). In addition, online interventions have already demonstrated their abilities to reduce other individual and social treatment barriers, given that they can be used any time privately the treatment-seeking individual feels the need for help, they are cost-effective or free, and easy-to-use (Baumgartner et al., 2019; Haug et al., 2018; Herrero et al., 2019; Weisel et al., 2018). Despite recent calls for randomized controlled trials to examine the effectiveness of interventions for PPU (Griffin et al., 2021; Grubbs et al., 2020) and the advantages of online interventions, compared to traditional interventions, no prior study examined the efficacy of online interventions for PPU.

As a first step in the field, the present study aimed to document the feasibility and initial effectiveness of an online self-help program to reduce PPU, considering previous recommendations (Arain, Campbell, Cooper, \& Lancaster, 2010; Bowen et al., 2009; Orsmond \& Cohn, 2015; Rounsaville et al., 2001). To provide preliminary findings of the effectiveness of the intervention, as the primary outcome, we examined the change in participants' PPU between baseline and six-week follow-up assessments, compared to a waitlist control condition. We hypothesized that participants in the intervention condition would report a decrease, while participants in the control condition would not report significant changes in their PPU over time. The secondary outcome measures included positive changes in participants' pornography use frequency, self-reported addiction, cravings, moral incongruence, time spent with pornography per session, and self-efficacy to avoid pornography use. We hypothesized that participants in the intervention condition would report beneficial changes in the secondary outcomes over time, while participants in the control condition would not report significant changes over time. ${ }^{1}$

\section{METHODS}

\section{Study design}

This study used a two-armed randomized controlled trial study design, examining the feasibility and potential efficacy

${ }^{1}$ Given high attrition rates, we needed to deviate from the analysis plan published in the study protocol paper (Böthe, Baumgartner, et al., 2020) and focused only on pornography use-related characteristics. 
of a PPU online intervention, with a waitlist control condition and follow-up assessments right after the end of the six-weeklong intervention. Participants were randomized after completing the baseline measures at an individual level by an automated, computer-based algorithm on the intervention website with a randomization list (1:1 ratio). Participants were informed about their condition assignment, but they were not aware of the study's hypotheses. Any blinding of study personnel was unwarranted, as they were not directly involved in the intervention. Participants in the intervention condition were granted immediate access to the intervention. Participants in the control condition received access to the intervention three months after completing the baseline measures. CONSORT guidelines were followed (see Appendix 1), the study was preregistered before starting the recruitment (https://osf.io/5tqkb), and a detailed study protocol was already published (Bőthe, Baumgartner, et al., 2020).

\section{Procedure and participants}

At the beginning of the study, we aimed to recruit people from Switzerland and Hungary mainly. However, participants from other countries were also invited and included in the study. Based on a priori sample size calculation with $80 \%$ power to detect small differences with an alpha error of $5 \%$ and two-tailed testing (Böthe, Baumgartner, et al., 2020), a minimum sample size of 242 participants (121 participants in each group) was deemed sufficient to detect differences between the intervention and control groups over time. We recruited a total of 361 participants on psychology news websites (e.g., PsyPost), social media sites (e.g., Reddit), and Google advertisements between February 2019 and December 2020, as the target sample size was reached.

Individuals who were 18 years old or older; had sufficient skills in the English language in reading and writing; had a valid email address and internet access at least for one hour each week; read the informed consent; and agreed to participate were included in the study. Participants were excluded from the study if they did not have a valid email address or did not complete the baseline questionnaire $(22$ participants). The final sample consisted of 264 participants (3.8\% women, $\left.M_{\text {age }}=33.2, S D=10.6\right)$. Most participants had a college or university degree $(77.3 \%)$, and the majority of them resided in the United States (37.9\%), England (15.5\%), or Canada (7.6\%). A total of $73.5 \%$ of the participants were heterosexual, and approximately half of them were in a romantic relationship. The detailed participant flow is shown in Fig. 1, and participants' sociodemographic characteristics are shown in Table 1.

\section{Intervention}

An automated, web-based intervention (Hands-off; www. hands-off.net) was developed by the authors based on the principles of motivational interviewing (Rollnick \& Miller, 1995), cognitive-behavioral therapy (Meichenbaum, 1977),

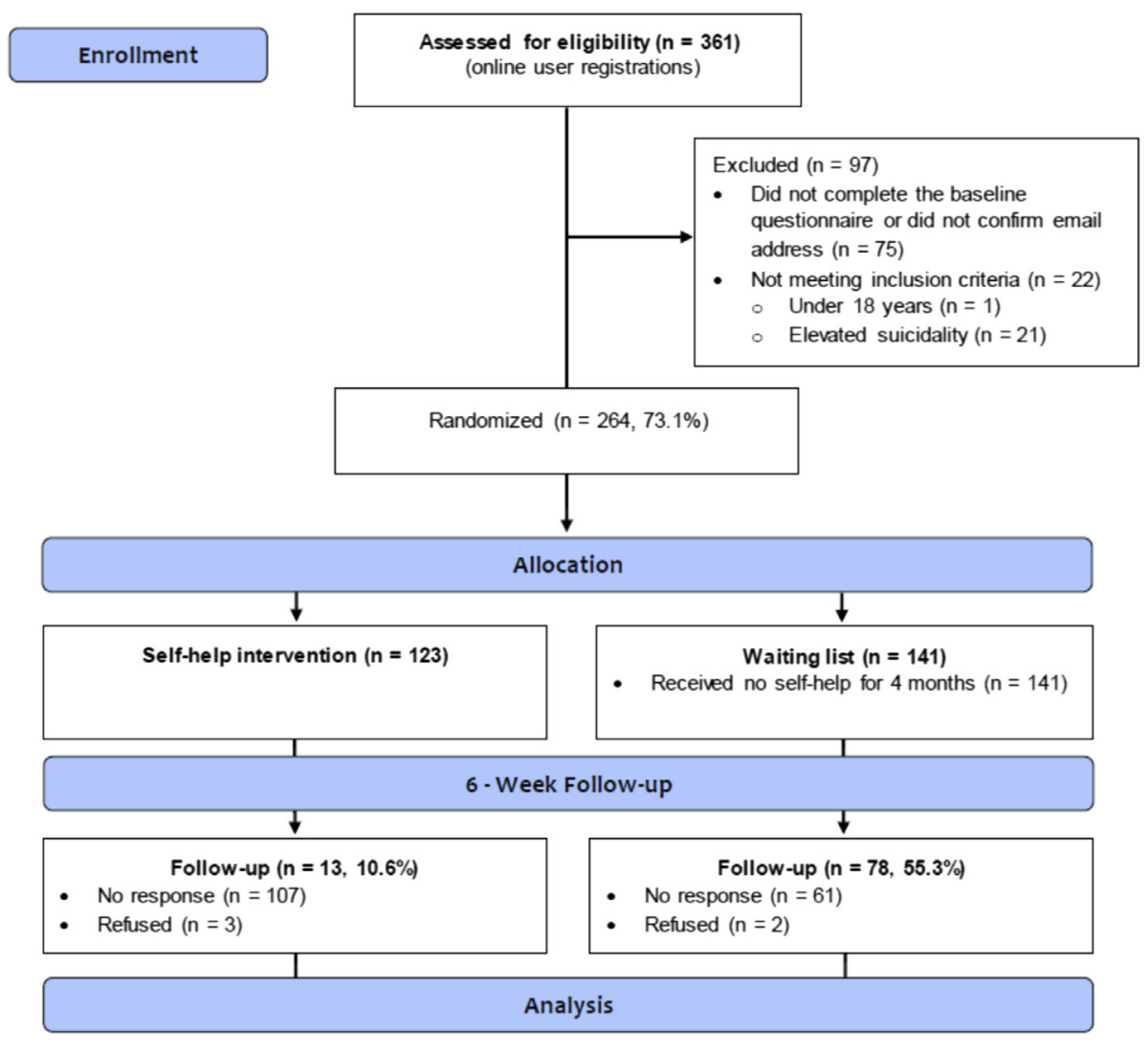

Fig. 1. Flowchart of Participants Based on the CONSORT Criteria

Note. CONSORT $=$ Consolidated Standards of Reporting Trials. 
Table 1. Baseline sociodemographic, pornography use-related, and psychological characteristics of participants in the intervention and control groups

\begin{tabular}{|c|c|c|c|c|}
\hline & $\begin{array}{l}\text { Intervention } \\
\text { group } \\
(n=123)\end{array}$ & $\begin{array}{l}\text { Waitlist control } \\
\text { group } \\
(n=141)\end{array}$ & $\begin{array}{c}\text { Total } \\
(N=264)\end{array}$ & $\begin{array}{c}\text { Statistical analysis } \\
\text { (Chi-Square Test, ANOVA) }\end{array}$ \\
\hline Gender, $n(\%)$ & & & & $\chi^{2}(2, N=264)=0.00, P=1.000$ \\
\hline Woman & $5(4.1)$ & $5(3.5)$ & $10(3.8)$ & \\
\hline Man & $118(95.9)$ & $136(96.5)$ & $254(96.2)$ & \\
\hline Age, $M(S D)$ & $33.3(11.5)$ & $33.1(9.9)$ & $33.2(10.6)$ & $F(2,262)=0.02, P=0.876$ \\
\hline Highest education, $n$ (\%) & & & & $\chi^{2}(3, N=264)=1.82, P=0.612$ \\
\hline Primary school & $0(0.0)$ & $2(1.4)$ & $2(0.8)$ & \\
\hline Vocational school & $2(1.6)$ & $2(1.4)$ & $4(1.5)$ & \\
\hline High school & $26(21.1)$ & $28(19.9)$ & $54(20.5)$ & \\
\hline College or university & $95(77.2)$ & $109(77.3)$ & $127(77.3)$ & \\
\hline Country of origin, $n(\%)$ & & & & $\chi^{2}(5, N=264)=3.71, P=0.592$ \\
\hline United States & $43(35.0)$ & $57(40.4)$ & $100(37.9)$ & \\
\hline England & $19(15.4)$ & $22(15.6)$ & $41(15.5)$ & \\
\hline Canada & $12(9.8)$ & $8(5.7)$ & $20(7.6)$ & \\
\hline Hungary & $10(8.1)$ & $8(5.7)$ & $18(6.8)$ & \\
\hline India & $3(2.4)$ & $7(5.0)$ & $10(3.8)$ & \\
\hline Other (combined $\left.{ }^{\mathrm{a}}\right)$ & $36(29.2)$ & $39(27.7)$ & $75(28.4)$ & \\
\hline Relationship status, $n$ (\%) & & & & $\chi^{2}(5, N=264)=10.01, P=0.075$ \\
\hline Single & $43(35.0)$ & $68(48.2)$ & $111(42.0)$ & \\
\hline In a relationship & $40(32.5)$ & $30(21.3)$ & $70(26.5)$ & \\
\hline Married & $37(30.1)$ & $34(24.1)$ & $71(26.9)$ & \\
\hline Engaged & $2(1.6)$ & $6(4.3)$ & $8(3.0)$ & \\
\hline Divorced & $0(0.0)$ & $2(1.4)$ & $2(0.8)$ & \\
\hline Other & $1(0.8)$ & $1(0.7)$ & $2(0.8)$ & \\
\hline Sexual orientation, $n(\%)$ & & & & $\chi^{2}(3, N=264)=4.58, P=0.205$ \\
\hline Heterosexual & $92(74.8)$ & $102(72.3)$ & $194(73.5)$ & \\
\hline Homosexual & $7(5.7)$ & $6(4.3)$ & $13(4.9)$ & \\
\hline Bisexual & $17(13.8)$ & $30(21.3)$ & $47(17.8)$ & \\
\hline Unsure & $7(5.7)$ & $3(2.1)$ & $10(3.8)$ & \\
\hline $\begin{array}{l}\text { Sought treatment for pornography use } \\
\text { previously, } n(\%)\end{array}$ & $40(32.5)$ & $48(34.0)$ & $88(33.3)$ & $\chi^{2}(1, N=264)=0.02, P=0.896$ \\
\hline $\begin{array}{l}\text { Problematic pornography use } \\
\quad \text { (Range } 0-126), M(S D)\end{array}$ & $80.5(16.6)$ & $81.1(20.4)$ & $80.8(18.7)$ & $F(1,262)=0.06, P=0.812$ \\
\hline Pornography use frequency, $n(\%)$ & & & & $\chi^{2}(5, N=264)=0.09, P=0.753$ \\
\hline$>7$ a week & $35(28.5)$ & $44(31.3)$ & $79(29.9)$ & \\
\hline 6-7 a week & $21(17.1)$ & $20(14.2)$ & $41(15.5)$ & \\
\hline $4-5$ a week & $22(17.9)$ & $25(17.7)$ & $47(17.8)$ & \\
\hline $2-3$ a week & $19(15.4)$ & $24(17.0)$ & $43(16.3)$ & \\
\hline weekly & $11(8.9)$ & $16(11.3)$ & $27(10.2)$ & \\
\hline Less frequently & $15(12.4)$ & $12(8.5)$ & $27(10.2)$ & \\
\hline $\begin{array}{l}\text { Time spent with pornography use per } \\
\text { session in minutes, } M(S D)\end{array}$ & $50.9(47.3)$ & $53.4(52.2)$ & $\begin{array}{c}52.2 \\
(50.47)\end{array}$ & $F(1,261)=0.15, P=0.696$ \\
\hline $\begin{array}{l}\text { Moral incongruence concerning } \\
\text { pornography use (Range 0-6), } \\
M(S D)\end{array}$ & $3.0(2.1)$ & $3.3(2.2)$ & $3.2(2.2)$ & $F(1,262)=0.87, P=0.351$ \\
\hline $\begin{array}{l}\text { Self-perceived pornography addiction } \\
\text { (Range 0-6), M (SD) }\end{array}$ & $4.6(1.5)$ & $4.7(1.4)$ & $4.7(1.4)$ & $F(1,262)=0.12, P=0.729$ \\
\hline $\begin{array}{l}\text { Pornography craving (Range 0-60), } \\
\qquad \begin{array}{l}\text { M (SD) }\end{array}\end{array}$ & $46.7(15.9)$ & $47.0(15.6)$ & $46.9(15.7)$ & $F(1,262)=0.04, P=0.840$ \\
\hline $\begin{array}{l}\text { Pornography avoidance self-efficacy } \\
\quad \text { (Range } 0-100), M(S D)\end{array}$ & $52.2(18.0)$ & $51.8(18.9)$ & $52.0(18.5)$ & $F(1,262)=0.04, P=0.834$ \\
\hline Sex mindset, (Range 5-30), $M(S D)$ & $13.0(5.2)$ & $13.7(5.1)$ & $13.4(5.2)$ & $F(1,262)=1.12, P=0.292$ \\
\hline Sexual satisfaction, (Range $0-4), M(S D)$ & $2.1(1.3)$ & $2.0(1.2)$ & $2.0(1.3)$ & $F(1,149)=0.25, P=0.617$ \\
\hline $\begin{array}{l}\text { Satisfaction with life, (Range 5-35), } \\
\qquad M(S D)\end{array}$ & $18.9(7.5)$ & $17.2(7.6)$ & $18.0(7.6)$ & $F(1,262)=3.31, P=0.070$ \\
\hline $\begin{array}{l}\left.\text { Self-report adult } A D H D^{\mathrm{b}} \text { (Range } 0-24\right) \text {, } \\
\quad M(S D)\end{array}$ & $12.0(4.2)$ & $12.1(4.5)$ & $12.0(4.4)$ & $F(1,262)=0.05, P=0.827$ \\
\hline
\end{tabular}


Table 1. Continued

\begin{tabular}{|c|c|c|c|c|}
\hline & $\begin{array}{l}\text { Intervention } \\
\text { group } \\
(n=123)\end{array}$ & $\begin{array}{l}\text { Waitlist control } \\
\text { group } \\
(n=141)\end{array}$ & $\begin{array}{c}\text { Total } \\
(N=264)\end{array}$ & $\begin{array}{c}\text { Statistical analysis } \\
\text { (Chi-Square Test, ANOVA) }\end{array}$ \\
\hline $\begin{array}{l}\text { Alcohol-related problems, (Range } 0-45) \text {, } \\
\qquad M(S D)\end{array}$ & $2.6(5.9)$ & $2.6(4.4)$ & $2.6(5.1)$ & $F(1,262)=0.00, P=0.973$ \\
\hline $\begin{array}{l}\text { Psychiatric symptoms (depressive, anxiety, } \\
\text { and somatization symptoms) } \\
\text { (Range } 0-72), M(S D)\end{array}$ & $18.3(12.5)$ & $20.0(11.5)$ & $19.2(12.0)$ & $F(1,262)=1.23, P=0.268$ \\
\hline Positive emotions, (Range 0-20), M (SD) & $15.0(3.5)$ & $14.9(4.3)$ & $14.9(4.0)$ & $F(1,262)=0.08, P=0.780$ \\
\hline Negative emotions, (Range 0-20), M (SD) & $17.3(4.0)$ & $17.2(4.6)$ & $17.2(4.3)$ & $F(1,262)=0.04, P=0.845$ \\
\hline Cannabis use $e^{c}, n(\%)$ & & & & $\chi^{2}(4, N=264)=8.01, P=0.091$ \\
\hline Never & $84(68.3)$ & $94(66.7)$ & $178(67.4)$ & \\
\hline Once or twice & $20(16.3)$ & $14(9.9)$ & $34(12.9)$ & \\
\hline Monthly & $4(3.3)$ & $8(5.7)$ & $12(4.5)$ & \\
\hline Weekly & $9(7.3)$ & $7(5.0)$ & $16(6.1)$ & \\
\hline Daily or almost daily & $6(4.9)$ & $16(12.8)$ & $24(9.1)$ & \\
\hline Prescription stimulants use $e^{c}, n(\%)$ & & & & $\chi^{2}(4, N=264)=0.54, P=0.464$ \\
\hline Never & $104(84.6)$ & $114(80.9)$ & $218(82.6)$ & \\
\hline Once or twice & $2(1.6)$ & $2(1.4)$ & $4(1.5)$ & \\
\hline Monthly & $0(0.0)$ & $0(0.0)$ & $0(0.0)$ & \\
\hline Weekly & $1(0.8)$ & $5(3.5)$ & $6(2.3)$ & \\
\hline Daily or almost daily & $16(13.0)$ & $20(14.2)$ & $36(13.6)$ & \\
\hline
\end{tabular}

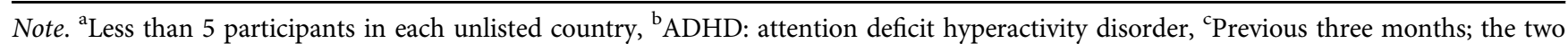
most commonly used substances (i.e., cannabis and prescription stimulants) are included in table. $M=$ mean, $S D=$ standard deviation.

mindfulness techniques (Altman, 2014), "wise" social-psychological interventions (Yeager \& Walton, 2011; Walton, 2014; Walton \& Wilson, 2018), and previous online interventions developed by the Swiss Research Institute for Public Health and Addiction that effectively reduced substance use, alcohol use, and problematic gambling (Baumgartner et al., 2019; Schaub et al., 2013, 2016). The intervention included six modules and one booster module. The six core modules were required to be completed in their intended order, and the booster module was available for participants to be completed one month after finishing the sixth module. Participants were instructed to complete one module each week and were encouraged to repeat any modules they found helpful. Modules' completion took between 45 and $60 \mathrm{~min}$ on average.

The first module gave a general overview of the intervention and motivated participants to reflect on their pornography use. The second module helped participants identify risk situations that might result in pornography use and taught strategies for dealing with them. The third module reflected on how to change pornography use habits and integrate pleasurable activities into participants' everyday lives. The fourth module concentrated on identifying triggers for cravings and taught strategies to reduce cravings. The fifth module introduced automatic negative thoughts and frequent common thinking errors, and strategies to challenge automatic negative and develop balanced thoughts. The sixth module reviewed the previous modules' content and participants' achievements and helped them plan strategies to prevent relapses. The booster module reviewed participants' past four weeks and provided participants the opportunity to review their past months and plan to preserve success in the long run. In addition, four fictional companions representing typical problematic pornography users were included in the modules to encourage reflection on specific questions.

Besides the intervention modules, the program included a dashboard which was the main page of the intervention. It provided helpful information for participants (e.g., dates of the follow-up assessments, activity planner, access to pornography use diary). A daily diary was also embedded on the website, assessing participants' targeted and actual pornography use frequency per day and mood. A personal graph was presented for participants for visual feedback. Safety measures (e.g., emergency contacts) and other elements (e.g., participants could revisit some of their inputs to specific questions in the intervention modules) were included in the intervention.

Participants in the waitlist control condition were provided the opportunity to participate in the intervention three months after completing the baseline survey. Similarly to participants in the intervention condition, participants in the control condition also completed baseline and follow-up measures.

\section{Measures}

Primary outcome. The primary outcome was self-reported scores on the Problematic Pornography Consumption Scale 
(PPCS) (Bőthe, Tóth-Király, et al., 2018). The PPCS assesses PPU with 18 items; participants indicated their answers on seven-point scales ( $1=$ "never"; $7=$ "all the time"; $\alpha=$ 0.90). A score of 76 (out of 126) or higher indicates a high risk of PPU.

Secondary outcomes. Pornography use frequency ${ }^{2}$, duration of pornography use per each session (Böthe, Bartók, et al., 2018; Böthe et al., 2021), perceived addiction and moral incongruence regarding pornography use (Grubbs, Kraus, \& Perry, 2019). Moreover, the 12-item Pornography Craving Questionnaire (PCQ; $\alpha=0.88$ ) (Kraus \& Rosenberg, 2014), and the 18-item Pornography-Use Avoidance Self-Efficacy Scale (PASS; $\alpha=0.90$ ) (Kraus, Rosenberg, Martino, Nich, \& Potenza, 2017) were assessed as secondary outcomes in this study.

Other variables. Participants' sociodemographic information (e.g., gender, age, relationship status, and sexual orientation), sexuality-related questions (e.g., number of lifetime sexual partners), and previous treatment-seeking for PPU were assessed at baseline (Böthe, Bartók, et al., 2018; Bőthe et al., 2021).

The one-item sexual satisfaction measure (Mark, Herbenick, Fortenberry, Sanders, \& Reece, 2014), the five-item Sex Mindset Scale (SMS; $\alpha=0.81$ ) (Bőthe, Tóth-Király, Demetrovics, \& Orosz, 2017), the five-item Satisfaction with Life Scale (SWLS; $\alpha=0.89$ ) (Diener, Emmons, Larsen, \& Griffin, 1985), and the ten-item Positive and Negative Affect Scale (PANAS; $\alpha_{\text {positive }}=0.43, \alpha_{\text {negative }}=0.44$ ) (Gyollai, Simor, Köteles, \& Demetrovics, 2011) were measured. The 18-item Brief Symptom Inventory (BSI-18; $\alpha=0.89$ ) (Asner-Self, Schreiber, \& Marotta, 2006), the six-item Adult ADHD Self-report Screening Scale for DSM-5 (ASRS-5; $\alpha=$ 0.72) (Ustun et al., 2017), the ten-item NIDA Assist (NIDA) (Group, 2002), the 15-item Alcohol-Related Problems: Short Inventory of Problems (SIP; $\alpha=0.94$ ) (Miller, Tonigan, \& Longabaugh, 1995), the five-item P4 Suicidality Screener (P4) (Dube, Kroenke, Bair, Theobald, \& Williams, 2010) were included in the study.

Moreover, after completing each module, participants were asked to rate the usefulness, understandability, length, appearance, likelihood of quitting the module before finishing the module, likelihood of quitting the program after finishing the module, and provide an overall rating. Participants rated each statement on a $0-100 \%$ scale. Higher scores indicate more positive attitudes in the case of usefulness, understandability, appearance, and overall rating. In the case of length and quitting questions, higher scores indicate more negative attitudes. Participants could also add qualitative feedback after finishing each module concerning the most and least useful parts and exercises, what they would change in the module, and write any other comments

\footnotetext{
${ }^{2}$ As pornography use frequency was assessed on an ordinal scale, we recoded this variable in the analyses: "weekly" $=1$; " $2-3$ times a week" $=2.5$; "4-5 times a week" $=4.5$; " $6-7$ times a week" $=6.5$; "more than 7 times a week" $=7.5$.
}

they had. For measurement details, see the study protocol (Böthe, Baumgartner, et al., 2020).

\section{Statistical analyses}

Although we originally planned to analyze the data on an intention-to-treat basis (Böthe, Baumgartner, et al., 2020), we could not conduct the analysis due to high attrition (see Fig. 1). Therefore, we used a treatment-of-the-treated, complete case analysis focusing on the pre-intervention and postintervention follow-up data six weeks after baseline (i.e., sixweek follow-up). Descriptive statistics were computed in $\mathrm{R}$ version 3.6.1 (R Core Team, 2019). To compare the baseline characteristics of participants in the control and intervention groups, we conducted chi-square tests and ANOVAs, depending on the outcome variable (i.e., categorical, ordinal, or continuous). For investigating possible treatment effects, multivariable linear regression models were generated and tested on a complete case basis, using the package "stats" in R. Change scores between baseline and 6-week follow-up served as dependent variables for the outcomes, with study condition set as the independent variable. Each outcome was adjusted for its baseline value.

\section{Ethics}

The authors assert that all procedures contributing to this work comply with the ethical standards of the relevant national and institutional committees on human experimentation and with the Helsinki Declaration. The present research was approved by the Institutional Ethical Review Board of the Eötvös Loránd University (2018/249-2). All participants were informed about the study, and all provided informed consent.

\section{RESULTS}

\section{Participation flow, and overall and differential attrition}

Figure 1 overviews the trial flow. Between February 2019 and December 2020, 361 potential participants were recruited, of which $26.9 \%$ were ineligible to participate in the study or did not complete the baseline questionnaire. Therefore, 264 participants were randomized and assigned to either the selfhelp intervention $(n=123)$ or the waitlist control condition $(n=141)$. The six-week follow-up was completed by 91 participants $(34.5 \%$ of the initial sample). There were significant differences in the dropout rates between the intervention and control groups, with only $11 \%$ of the intervention group completing the six-week follow-up compared to $55 \%$ in the control group $\left(\chi^{2}(1, N=264)=\right.$ 56.27, $P<0.001)$. We further examined overall attrition (independent of condition) and differential attrition (dependent on condition). Concerning overall attrition, participants retained in both conditions, as compared to those not retained, did not have significantly different demographic and psychological characteristics, except for satisfaction with life $(t(197.4)=-2.07, P=0.039)$. 
Participants dropping out from the study reported significantly higher satisfaction with their life at baseline $(M=$ $18.68, S D=7.76)$ than those retained $(M=16.70, S D=$ 7.12). Concerning differential attrition, no significant differences were observed between those who dropped out and completed the follow-up measurement in the control group (all $p s>0.180$ ). Moreover, no significant differences were revealed between those who completed vs. did not complete the follow-up assessment in the intervention group, except for pornography craving $(t(17.7)=-2.45, P=0.025)$. Participants dropping out from the intervention reported a significantly higher pornography craving score at baseline $(M=47.59, S D=16.07)$ than those retained $(M=38.69$, $S D=11.86)$.

\section{Participants' characteristics}

Concerning the primary outcome, participants reported high levels of PPU $(M=80.8, S D=33.3)$, which is above the suggested cut-off score (i.e., 76), and one-third of the participants had sought treatment for their pornography use before. Most participants used pornography regularly, with $30 \%$ of them using it more than seven times a week, and on average, they spent almost an hour $(M=52 \mathrm{~min}, S D=50)$ with pornography use per session. Participants reported high levels of self-perceived pornography addiction $(M=4.7, S D=1.4)$, pornography craving $(M=46.9$, $S D=15.7)$, and low levels of pornography avoidance selfefficacy $(M=52.0, S D=18.5)$. No significant differences were observed between the intervention and control group concerning their baseline sociodemographic, pornography use-related, and psychological characteristics. Participants' detailed characteristics can be seen in Table 1 .

Given the high attrition rate in the intervention group, we pushed forward the comparison of participants' characteristics and examined potential differences between participants in the intervention group who did not complete any modules $(n=41)$, completed only one module $(n=37)$, and completed more than one module $(n=45)$ (Appendix 2, Table A1.) No significant differences were observed between these groups, except for age. Participants were significantly younger in the group of those who only completed one module $(M=28.4, S D=8.8)$, compared to those who did not complete any modules $(M=35.4$,
$S D=11.7)$ and completed more than one module $(M=35.4, S D=12.2)$.

\section{Results of preliminary analysis and efficacy of the intervention}

Based on the complete case analysis (Tables 2 and 3), participants in the intervention group, compared to the control group, reported significantly lower levels of PPU $(B=-19.33 ; \mathrm{CI}=-28.75,-9.91 ; P<0.001, d=1.32)$. In the intervention group, participants' PPU scores were under the suggested cut-off score (76 points) at the six-week follow-up $(M=64.00, S D=14.81)$, while the control group participants' PPU scores were still above the cut-off $(M=80.06$, $S D=20.77)$. Similarly, pornography use frequency was significantly lower in the intervention group $(M=2.44, S D$ $=1.69)$ at the six-week follow-up $(B=-2.88$; $\mathrm{CI}=-4.11$, $-1.65 ; P<0.001, d=1.65)$, while participants' pornography use frequency remained unchanged in the control group $(M$ $=5.12, S D=2.35$ ). Compared to the control group, participants in the intervention group reported lower selfperceived pornography addiction $(B=-1.04$; $\mathrm{CI}=-1.83$, $-0.24, P=0.010, d=0.85)$ and higher pornography avoidance self-efficacy at the six-week follow-up $(B=17.89$; $\mathrm{CI}=7.22,28.56, P=0.001, d=0.87)$, and significantly lower levels of pornography craving $(B=-10.45$; $\mathrm{CI}=-18.91,-1.99, P=0.020, d=0.40)$. However, participants' moral incongruence toward pornography use and time spent with pornography use on each session did not change significantly $(B=0.12 ; P=0.530)$.

\section{Adherence and participants' feedback on the intervention}

Two-thirds of the participants in the intervention group completed the first module of the intervention, while only $12 \%$ of them completed the sixth module, with a gradual decrease in completion (see Fig. 2). On average, participants completed 1.73 modules $(S D=2.07)$. Participants evaluated all modules positively in the intervention in general $(M=$ 73.82-82.00). Similarly high scores were reported concerning the modules' usefulness $(M=74.58-82.67)$, understandability $(M=81.11-94.00)$, and appearance $(M=$ 78.89-88.67). Participants reported high satisfaction with

Table 2. Results of the complete case analysis concerning pornography use-related variables

\begin{tabular}{|c|c|c|c|}
\hline \multirow[b]{2}{*}{ Variables } & \multicolumn{3}{|c|}{ 6-week follow-up } \\
\hline & B $(95 \% \mathrm{CI})$ & $\beta(95 \% \mathrm{CI})$ & $P$ \\
\hline Problematic pornography use & $-19.33(-28.75,-9.91)$ & $-1.12(-1.67,-0.58)$ & $<0.001$ \\
\hline Pornography craving & $-10.45(-18.91,-1.99)$ & $-0.71(-1.28,-0.13)$ & 0.02 \\
\hline $\begin{array}{l}\text { Moral incongruence concerning } \\
\text { pornography use }\end{array}$ & $0.61(-0.17,1.40)$ & $0.47(-0.14,1.09)$ & 0.12 \\
\hline Self-perceived pornography addiction & $-1.04(-1.83,-0.24)$ & $-0.66(-1.16,-0.15)$ & 0.01 \\
\hline Pornography avoidance self-efficacy & $17.89(7.22,28.56)$ & $0.95(0.39,1.53)$ & 0.001 \\
\hline Pornography use frequency last 7 days & $-2.88(-4.11,-1.65)$ & $-1.44(-2.06,-0.83)$ & $<0.001$ \\
\hline $\begin{array}{l}\text { Time spent with pornography use per } \\
\text { session in minutes }\end{array}$ & $-7.75(-32.16,16.66)$ & $-0.16(-0.66,0.34)$ & 0.53 \\
\hline
\end{tabular}

Note. $95 \%$ CI $=95 \%$ confidence interval. 
Table 3. Comparison of the control and intervention groups concerning pornography use-related variables based on the complete case analysis

\begin{tabular}{|c|c|c|c|c|c|}
\hline \multirow[b]{2}{*}{ Variables } & \multicolumn{2}{|c|}{ Waitlist control group $(n=73)$} & \multicolumn{2}{|c|}{ Intervention group $(n=13)$} & \multirow[b]{2}{*}{ Cohen's $d^{\mathrm{a}}(95 \% \mathrm{CI})$} \\
\hline & $\begin{array}{l}\text { Baseline } \\
M(S D)\end{array}$ & $\begin{array}{l}\text { 6-week follow-up } \\
M(S D)\end{array}$ & $\begin{array}{l}\text { Baseline } \\
M(S D)\end{array}$ & $\begin{array}{l}\text { 6-week follow-up } \\
M(S D)\end{array}$ & \\
\hline Problematic pornography use & $79.63(20.30)$ & $80.06(20.77)$ & $85.31(19.43)$ & $64.00(14.81)$ & $1.32(0.68,1.92)$ \\
\hline Pornography craving & $46.58(16.64)$ & $47.40(15.80)$ & $38.69(11.86)$ & $31.64(12.19)$ & $0.40(-0.20,0.98)$ \\
\hline $\begin{array}{l}\text { Moral incongruence concerning } \\
\text { pornography use }\end{array}$ & $3.29(2.20)$ & $3.18(2.18)$ & $2.85(2.03)$ & $3.63(1.96)$ & $-0.51(-1.09,0.10)$ \\
\hline Self-perceived pornography addiction & $4.67(1.47)$ & $4.90(1.31)$ & $4.92(0.86)$ & $4.00(1.34)$ & $0.85(0.24,1.44)$ \\
\hline Pornography avoidance self-efficacy & $52.54(19.77)$ & $51.63(20.75)$ & $56.32(17.90)$ & $73.08(17.55)$ & $-0.87(-1.46,-0.25)$ \\
\hline $\begin{array}{l}\text { Pornography use frequency in the last } 7 \\
\text { days }\end{array}$ & $4.94(2.44)$ & $5.12(2.35)$ & $5.36(2.17)$ & $2.44(1.69)$ & $1.65(0.99,2.26)$ \\
\hline $\begin{array}{l}\text { Time spent with pornography use per } \\
\text { session in minutes }\end{array}$ & $56.81(62.21)$ & $54.16(53.48)$ & $37.85(40.49)$ & $36.54(34.00)$ & $-0.02(-0.61,0.56)$ \\
\hline
\end{tabular}

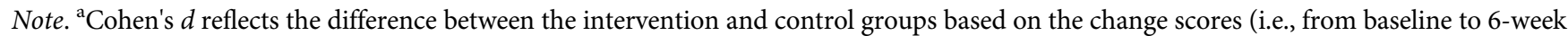
follow-up). $95 \% \mathrm{CI}=95 \%$ confidence interval. $M=$ mean, $S D=$ standard deviation.

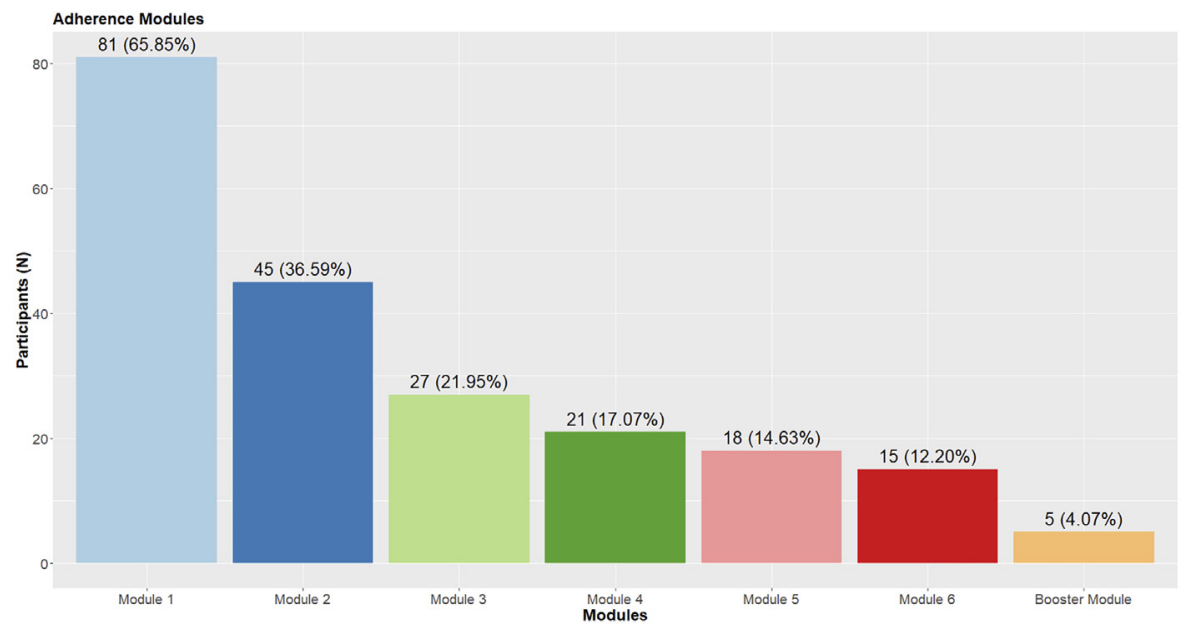

Fig. 2. Completion of modules in the intervention group

the modules' length $(M=8.00-33.82)$ and a low likelihood of quitting before finishing the given module $(M=6.00-$ 26.76) or quitting the program after finishing the module $(M$ = 3.33-16.47) (Table 4). Qualitative feedback corroborated participants' quantitative answers (Table 5). Participants mentioned finding useful those components of given modules that were aimed to be addressed (e.g., identification of advantages and disadvantages of pornography use in module 1). Nevertheless, participants also mentioned some components and characteristics of the intervention (e.g., not having relatively old companions) that should be changed. Moreover, some tasks were considered useful by some participants, while others considered them less useful (e.g., advising a companion in module 2).

\section{DISCUSSION}

Despite PPU being prevalent, no previous study has examined the effectiveness of evidence-based, online interventions for PPU using rigorous methods (Griffin et al., 2021; Grubbs et al., 2020; Grubbs \& Kraus, 2021). We examined the feasibility and initial efficacy of an online PPU intervention using a randomized controlled trial study design (Rounsaville et al., 2001). Participants evaluated the intervention positively and reported significantly lower PPU and beneficial changes in other pornography use-related characteristics at the sixweek follow-up, compared to the control group, indicating the potential effectiveness of the intervention. However, the attrition was high, especially in the intervention group, limiting the generalizability of the findings. Possible ways to strengthen the intervention were identified.

\section{Preliminary effectiveness of the intervention}

The recruitment was successful, and the target sample size was reached within 23 months. Participants' sociodemographic characteristics (e.g., gender, age, relationship status, sexual orientation) were similar to previous PPU treatmentseeking samples (Gola et al., 2016; Kraus et al., 2016; Lewczuk 
Table 4. Participants feedback on the usefulness, length, overall rating of the modules

\begin{tabular}{|c|c|c|c|c|c|c|c|}
\hline Modules $^{\mathrm{a}, \mathrm{b}}$ & $\begin{array}{l}\text { Usefulness } \\
M(S D)^{c}\end{array}$ & $\begin{array}{l}\text { Understandability } \\
\qquad M(S D)^{c}\end{array}$ & $\begin{array}{l}\text { Length } \\
M(S D)^{c}\end{array}$ & $\begin{array}{l}\text { Appearance } \\
M(S D)^{c}\end{array}$ & $\begin{array}{l}\text { Likelihood of quitting the module } \\
\text { before finishing the module } \\
\qquad M(S D)^{c}\end{array}$ & $\begin{array}{l}\text { Likelihood of quitting the program } \\
\text { after finishing the module } \\
\qquad M(S D)^{c}\end{array}$ & $\begin{array}{l}\text { Overall } \\
\text { rating } \\
M(S D)^{c}\end{array}$ \\
\hline $\begin{array}{l}\text { Module 1: Introduction and the } \\
\text { possibility of change }(n=120)\end{array}$ & $\begin{array}{l}74.58 \\
(22.82)\end{array}$ & $86.92(17.72)$ & $\begin{array}{c}28.75 \\
(30.61)\end{array}$ & $\begin{array}{c}81.33 \\
(22.52)\end{array}$ & $25.50(26.05)$ & $16.25(22.61)$ & $\begin{array}{l}78.17 \\
(20.94)\end{array}$ \\
\hline $\begin{array}{l}\text { Module 2: Why do I watch porn, } \\
\text { and how can I change it? } \\
\text { Identifying internal and external } \\
\text { risk situations }(n=54)\end{array}$ & $\begin{array}{c}78.15 \\
(24.58)\end{array}$ & 84.07 (19.48) & $\begin{array}{c}22.78 \\
(26.16)\end{array}$ & $\begin{array}{c}78.89 \\
(22.88)\end{array}$ & $23.89(28.38)$ & $11.48(17.20)$ & $\begin{array}{c}77.59 \\
(27.40)\end{array}$ \\
\hline $\begin{array}{l}\text { Module 3: How to feel better } \\
\text { without porn? }(n=34)\end{array}$ & $\begin{array}{c}78.82 \\
(18.38)\end{array}$ & $87.94(14.73)$ & $\begin{array}{c}33.82 \\
(29.13)\end{array}$ & $\begin{array}{c}85.59 \\
(14.81)\end{array}$ & $26.76(27.93)$ & $16.47(24.73)$ & $\begin{array}{l}73.82 \\
(30.55)\end{array}$ \\
\hline $\begin{array}{l}\text { Module 4: What can I do about my } \\
\text { cravings? }(n=22)\end{array}$ & $\begin{array}{c}82.27 \\
(20.45)\end{array}$ & $82.73(20.04)$ & $\begin{array}{c}15.00 \\
(24.83)\end{array}$ & $\begin{array}{c}85.00 \\
(18.20)\end{array}$ & $13.18(19.85)$ & $9.09(16.01)$ & $\begin{array}{l}78.18 \\
(28.89)\end{array}$ \\
\hline $\begin{array}{l}\text { Module 5: Behaviors, Emotions, } \\
\text { and Thoughts (BET): I BET you } \\
\text { can do it }(n=18)\end{array}$ & $\begin{array}{c}77.22 \\
(31.59)\end{array}$ & $81.11(22.72)$ & $\begin{array}{c}15.56 \\
(22.29)\end{array}$ & $\begin{array}{c}81.11 \\
(22.72)\end{array}$ & $11.67(24.55)$ & $3.33(5.90)$ & $\begin{array}{l}79.44 \\
(26.89)\end{array}$ \\
\hline $\begin{array}{l}\text { Module 6: How to preserve your } \\
\text { success? }(n=15)\end{array}$ & $\begin{array}{l}82.67 \\
(18.70)\end{array}$ & $94.00(9.86)$ & $\begin{array}{c}8.00 \\
(17.40)\end{array}$ & $\begin{array}{c}88.67 \\
(14.57)\end{array}$ & $6.00(18.05)$ & $6.67(20.59)$ & $\begin{array}{l}82.00 \\
(27.83)\end{array}$ \\
\hline
\end{tabular}

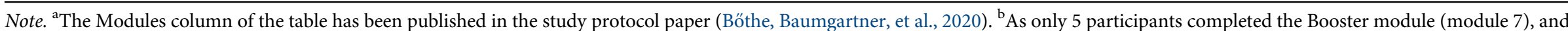
it took place four weeks after finishing the intervention, we did not include it in the present analysis. The number of participants who provided feedback for each module is presented in parentheses after each module's title. As participants in the waitlist control condition were provided the opportunity to participate in the intervention three months after completing the baseline survey, their responses, and active participants' responses are also included in this table for comprehensiveness, resulting in larger subsample sizes than number of participants completing each module in the intervention group in Fig. 2. ${ }^{c}$ The range of response options for all questions was between $0 \%$ and $100 \%$. Higher scores indicate more positive attitudes in the case of usefulness, understandability, appearance, and overall rating. In the case of length and quitting questions, higher scores indicate more negative attitudes. As 0 was the default value for all questions, we removed those participants' data from this analysis who had a 0 answer for all questions. $M=$ mean, $S D=$ standard deviation. 
Table 5. Modules in the intervention and summary of participants' qualitative feedback

\begin{tabular}{lc} 
Modules $^{\mathrm{a}, \mathrm{b}}$ & Content $^{\mathrm{a}}$ \\
\hline $\begin{array}{l}\text { Module 1: Introduction and the } \\
\text { possibility of change ( } n \text { fffff } \\
120)\end{array}$ & - General overview \\
& Introduction to fictional \\
companions \\
-
\end{tabular}

Module 2: Why do I watch porn, and how can I change it? Identifying internal and external risk situations $(n=54)$

- Identification of the internal and external risk situations that can lead to pornography use

- Learning how to deal with
Components mentioned as most useful $^{\mathrm{c}}$

- Reflecting on past success

- Identification of pros and cons of pornography use

- Identification of reasons to quit pornography use

- Looking at the antecedents and consequences of

pornography use all at one time on the page

- Companions and reading about their experiences

- Interactive parts

- Diary, identifying resources that already have these risk situations
Module 3: How to feel better without porn? $(n=34)$

Module 4: What can I do about my cravings? $(n=$ 22)
- Learning how to change personal pornography using habits

- Learning how to integrate joyful activities into everyday life
- Identifying things to do instead of pornography use (fun activities)

- Bringing up earlier responses from the particfor quitting pornography use

- The realization that good habits can become lasting habits given time

- Knowledge that willpower can be changed

- Identification of personal triggers for cravings

- Learning strategies to reduce craving

ings work (e.g., visualizations)

- Learning about how to deal

\section{- Mindfulness}

- Listing the feelings followed by porn use

- Examples of companions

- Identification and reflection on triggers

- The break-down of how to tackle risk situations

- Giving advice to a companion ipant about the reasons

Components mentioned as least useful $^{\mathrm{c}}$

- Identification of pros and cons of pornography use

- Identification of resources

- Age (i.e., only relatively young companions) and credibility of companions

- High number of questions and typing tasks

- Too much reading and text

- Too generic examples

- Some components seem redundant

- More explanation is needed for some tasks

- No human interaction

- Listing habits the participant has already changed

- Giving advice to a companion

- Giving advice to future self

- Explaining mindfulness in own words, "too academical” examples (e.g., linked blogs), and already knowing about mindfulness

- Age (i.e., only relatively young companions) of companions

- Not mentioning "masturbation addiction"

- Some figures were too small on phones

- List of sports and free time activities

- Bringing up earlier responses from the participant with cravings
- Giving advice for future participants 
Table 5. Continued

\begin{tabular}{|c|c|c|c|}
\hline Modules $^{\mathrm{a}, \mathrm{b}}$ & Content $^{\mathrm{a}}$ & $\begin{array}{c}\text { Components mentioned as most } \\
\text { useful }^{c}\end{array}$ & $\begin{array}{c}\text { Components mentioned as least } \\
\text { useful }^{c}\end{array}$ \\
\hline $\begin{array}{l}\text { Module 5: Behaviors, Emo- } \\
\text { tions, and Thoughts } \\
\text { (BET): I BET you can do it } \\
(n=18)\end{array}$ & $\begin{array}{l}\text { - Getting to know automatic } \\
\text { negative thoughts and the } \\
\text { most frequent common } \\
\text { thinking errors } \\
\text { - Learning about the re- } \\
\text { lations between one's } \\
\text { thoughts, emotions, and } \\
\text { pornography use } \\
\text { - Learning strategies to } \\
\text { challenge automatic } \\
\text { negative thoughts and } \\
\text { develop balanced } \\
\text { thoughts }\end{array}$ & $\begin{array}{c}\text { - Learning about automatic } \\
\text { negative thoughts } \\
\text { - Explanations and examples } \\
\text { - Learning about how to deal } \\
\text { with automatic negative } \\
\text { thoughts }\end{array}$ & $\begin{array}{c}\text { - Keeping a thought diary } \\
\text { (pdf) on a shared com- } \\
\text { puter might be problem- } \\
\text { atic }\end{array}$ \\
\hline $\begin{array}{l}\text { Module 6: How to preserve } \\
\text { your success? }(n=15)\end{array}$ & $\begin{array}{c}\text { - Reviewing the main con- } \\
\text { tents of the previous } \\
\text { modules } \\
\text { - Identification of one's } \\
\text { toughest moments in } \\
\text { the program and how } \\
\text { he/she overcame them } \\
\text { - Planning strategies to pre- } \\
\text { vent relapses to previous } \\
\text { pornography use habits }\end{array}$ & $\begin{array}{l}\text { - Reviewing previous con- } \\
\text { tent and opportunity to } \\
\text { go back to earlier modules } \\
\text { - Best strategies part } \\
\text { - Prevention plan }\end{array}$ & - NA \\
\hline
\end{tabular}

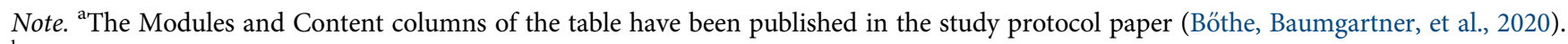

${ }^{\mathrm{b}}$ As only 5 participants completed the Booster module (module 7), and it took place four weeks after finishing the intervention, we did not include it in the present analysis. ${ }^{c}$ As the number of participants gradually decreased, the number of and variety of mentioned topics in the feedback also decreased. The number of participants who provided qualitative feedback for each module is presented in parentheses after each module's title. As participants in the waitlist control condition were provided the opportunity to participate in the intervention three months after completing the baseline survey, their responses, and active participants' responses are also included in this table for comprehensiveness, resulting in larger subsample sizes than number of participants completing each module in the intervention group in Fig. 2.

et al., 2017). On average, participants reported higher PPU scores than the recommended cut-off (Böthe, Tóth-Király, et al., 2018), and reported high pornography use frequency (i.e., $45 \%$ of participants used pornography daily or more often) at baseline, suggesting that we had successfully identified the target population (Orsmond \& Cohn, 2015). Concerning our primary outcome, in line with our hypothesis (Bőthe, Baumgartner, et al., 2020), PPU significantly decreased in the intervention group at the six-week follow-up, compared to the control group. Regarding the secondary outcomes, findings were in line with the hypothesized changes; participants in the intervention group reported significantly lower pornography use frequency, self-perceived pornography addiction and craving, and higher pornography avoidance self-efficacy at the six-week follow-up. However, participants' moral incongruence toward pornography use and time spent with pornography use on each session did not change significantly, presumably as these topics were not as pronounced in the intervention as others. Although our analyses were exploratory, given the small sample size and low statistical power, our preliminary findings suggest that the intervention hold promise in reducing participants' PPU
(Bowen et al., 2009; Orsmond \& Cohn, 2015; Rounsaville et al., 2001). Moreover, as our measures could detect the change in our primary and secondary outcomes, they provided evidence of being appropriate for the population and future studies (Orsmond \& Cohn, 2015).

\section{Overall and differential attrition rates, adherence, and potential reasons of dropout}

Although we expected high dropout rates based on the results of online intervention studies (Rooke, Copeland, Norberg, Hine, \& McCambridge, 2013; Schaub et al., 2015), the attrition was especially high in the intervention group, limiting the findings' generalizability. Specifically, 55\% of the participants completed the six-week follow-up in the control group, while only $11 \%$ completed it in the intervention group. When examining overall attrition, participants who completed the follow-up assessment and dropped out reported similar initial levels of sociodemographic and psychological characteristics, except for satisfaction with life. Participants dropping out from the study had higher initial life satisfaction, suggesting that those participants were 
retained who might have experienced more problems in their life in general. Concerning differential attrition, dropout analysis revealed that participants who provided follow-up data did not differ significantly from dropouts in their baseline characteristics in the control group. However, in line with previous findings (Gottlieb, Horwitz, Kraus, Segal, \& Viscoli, 1994; Panlilio et al., 2019), dropouts reported significantly higher pornography craving at baseline than participants who completed the intervention. As higher levels of dysregulated pornography use may be related to higher avoidant coping strategies (Lewczuk et al., 2020), for individuals with high pornography craving, participating in an online intervention that focuses on pornography use might be triggering. Thus, craving might play an important role in adherence and should be presented as soon as possible during the intervention. Another possibility might be to open all modules from the beginning of the intervention, or prepare personalized suggestions about the order of the modules for each participant based on their baseline survey results.

It is important to note that similar attrition rates were observed in PPU treatment-seeking men in a recent study. Similarly to our results, only $11 \%$ of the participants completed the follow-up survey after participating in an app-based intervention for PPU (Chen, Jiang, Luo, Kraus, \& Böthe, 2021). Based on follow-up interviews with participants dropping out from the study, several potential mechanisms were mentioned that might explain the high attrition, such as the unsuitability of reminders, feelings that pornography use-related problems did not change during the intervention, or using avoidance as a potential coping strategy (i.e., avoiding pornography-related content, including the follow-up surveys) (Chen et al., 2021). These explanations might apply to the present study as well. Moreover, the higher follow-up completion rate in the control group might result from the fact that participants in the control group were provided access to the intervention three months after completing the baseline survey. Therefore, these participants might have been more motivated to complete all surveys while waiting for the intervention, whereas participants in the intervention group did not have any incentives to complete the follow-up survey after receiving the intervention. However, future studies are needed to map other potential reasons for dropout.

When examining the adherence rate in the intervention group (Orsmond \& Cohn, 2015), a gradual decrease can be observed in completion from module to module (from $66 \%$ to $12 \%)$. Therefore, we examined potential differences between participants in the intervention group who did not complete any modules, completed only one module, and completed more than one module. Participants were significantly younger in the group of those who only completed one module, compared to those who did not complete any modules and completed more than one module. However, no other significant differences were observed in participants' sociodemographic, pornography use-related, or psychosocial characteristics. These findings suggest that no systematic attrition might have been present in the study (e.g., more severe cases dropping out of the study before completing any modules, or after completing only one module).

The results of the present study align with previous online interventions' findings concerning low adherence rates (Amann et al., 2018), presumably resulting from the absence of incentives. Thus, future studies should provide incentives for participants. Nevertheless, it should be noted that funding agencies usually demonstrate little interest in supporting pornography use research, limiting researchers' resources (Grubbs \& Kraus, 2021). Moreover, low adherence might also derive from the specific features of online interventions, such as the absence of personal relationships and personalized exercises, and participants receiving only email invitations to complete the follow-up surveys (Amann et al., 2018; Beintner, Emmerich, Vollert, Taylor, \& Jacobi, 2019). Although higher adherence might be achieved by calls or text message reminders, it would violate anonymity, which can be especially important for individuals with PPU who might experience great shame and guilt concerning their pornography use (Sniewski \& Farvid, 2020). This notion was supported by the fact that several participants used throwaway email accounts, corroborating participants' need for anonymity.

\section{Participants' feedback and potential changes in the intervention}

Participants evaluated the intervention positively concerning its usefulness, understandability, appearance, and length, illustrating the acceptability of the intervention (Bowen et al., 2009). These findings corroborated the results of previous online interventions, suggesting that evidencebased, online self-help materials may reduce treatment barriers and provide free and easy-to-use tools to reduce problematic behaviors (Baumgartner et al., 2019; Haug et al., 2018; Herrero et al., 2019; Weisel et al., 2018). Still, based on participants' feedback, some changes in study design and content of intervention are suggested for future research.

Participants found the craving and success preservation modules the most useful, further supporting the importance of focusing on craving in the first modules of the intervention. Participants were satisfied with the length of the modules in general. However, reported that the "how to feel better without pornography" module was too long. Yet, it needs to be noted that some participants find it helpful that several activity lists were included in this module. Thus, restructuring and reducing the length of this module might be beneficial, with keeping the activity lists. Participants found all modules understandable and were satisfied with their appearance. Still, they suggested adapting the intervention to a more mobile-friendly format (e.g., smaller figures), adding more explanation and specific examples to some tasks (e.g., previous successful efforts to change problematic behaviors), putting more emphasis on masturbation, and reducing the number of questions, typing tasks, and materials to read.

Other potential improvement targets may involve adding more companions to the intervention relate (e.g., 
older companions), as some participants did not find any companion to whom they could. In line with previous findings (Amann et al., 2018), some participants missed human interaction. Future studies may complement this intervention with social support, or guidance teams found effective in previous online interventions (Baumgartner et al., 2021; Zarski et al., 2016). The suggested changes for improving Hands-off may increase its potential effectiveness in future studies, and the findings extended our insights in designing effective online interventions for PPU in general.

\section{Limitations and future directions}

The majority of participants lived in the US, England, or Canada; were heterosexual men; were highly educated (i.e., had a college or university degree); and had a high socioeconomic status (i.e., the sample was Western, educated, industrialized, rich, and democratic, WEIRD), limiting the generalizability of the findings. Further examination is needed to examine the potential efficacy of the intervention in other non-WEIRD populations (Griffin et al., 2021; Klein et al., 2021). The high dropout rate, low adherence, and differences between those who completed and did not complete the follow-up assessment (e.g., higher levels of craving among those who dropped out from the intervention group) might also limit the conclusions drawn from our findings. As discussed above, several strategies (e.g., incentives) should be applied to retain higher adherence rates, providing the opportunity for more comprehensive analyses (e.g., including sexual wellbeing or general wellbeing, or other mental health-related variables). Lastly, no objective criteria were used to exclude participants from the study who had not demonstrated dysregulated, compulsive, or problematic pornography use, as the intervention was designed to be potentially effective in all groups of treatment-seeking individuals (e.g., individuals with dysregulated pornography use or individuals with self-perceived PPU due to moral incongruence towards pornography use) (Chen et al., 2021; Grubbs, Perry, Wilt, \& Reid, 2019; Kraus \& Sweeney, 2019). Therefore, it is possible that some individuals might have realized that their pornography use is not problematic or might have simply been interested in the content of the intervention without any objective or selfperceived PPU, resulting in high dropout rates. However, the number of these individuals should be low, as no significant differences were be observed in the baseline levels of PPU, self-perceived pornography addiction, and moral incongruence towards pornography use of individuals in the intervention group who did not complete any modules, completed only one module, or completed more than one module.

Our preliminary findings show potential for PPU treatment and provide a basis for future adequately powered randomized controlled trials following previously established guidelines and recommendations of evaluating the feasibility (stage I), effectiveness (stage II), and transportability (stage III) of new interventions (Rounsaville et al., 2001). As a next step (stage II), studies should evaluate the effectiveness of the Hands-off intervention using an adequately powered RCT study design with one or more active control conditions (e.g., comparing the intervention to traditional, offline treatment; self-help groups; or self-help books or online applications) (Becker, Haug, Sullivan, \& Schaub, 2014; Rounsaville et al., 2001; Weisel et al., 2019). Moreover, addressing the potential mechanisms underlying the effectiveness of the treatment (i.e., theory of change mechanisms, why and how the intervention is effective) would be beneficial in this step, especially as most previous studies on PPU have been conducted without strong theoretical models and integrating the understandings of PPU into larger theoretical frameworks (e.g., network models of psychopathologies) (Böthe, Lonza, Štulhofer, \& Demetrovics, 2020; Grubbs et al., 2020; Rounsaville et al., 2001; Werner, Štulhofer, Waldorp, \& Jurin, 2018).

After establishing the effectiveness of the intervention in at least two RCTs, an essential next step is the examination of the transportability of the intervention to different settings (stage III) (Rounsaville et al., 2001). For example, one key issue would be the evaluation of the generalizability of the intervention's effectiveness in non-WEIRD populations, among women and non-binary individuals, other cultures, or other languages (Griffin et al., 2021; Klein et al., 2021). Moreover, individuals' treatment-seeking for PPU may derive from actual behavioral dysregulation (i.e., PPU), moral incongruence towards pornography use (i.e., selfperceived PPU due to moral incongruence towards pornography use), or both (i.e., behavioral dysregulation and moral incongruence towards pornography use) (Grubbs et al., 2019; Grubbs \& Perry, 2019; Kraus \& Sweeney, 2019). Therefore, the intervention's effectiveness should be tested in all these populations. The intervention might also be adapted to meet the different treatment needs and goals of these populations (e.g., participants might be allocated to the most appropriate version of the intervention based on the results of their baseline survey, following a decision tree or algorithm of differential diagnosis and treatment) (Kraus \& Sweeney, 2019). Following the recommendations of the stage model of behavioral therapies research may help facilitate bridging the gap between research findings and clinical practice, and providing guidelines for choosing the most optimal treatment options for individuals with PPU (Rounsaville et al., 2001).

\section{CONCLUSIONS}

Preliminary results suggested that participants in the intervention group reported lower PPU, self-perceived pornography addiction, pornography use frequency, pornography craving, and better pornography avoidance self-efficacy compared to the control group. Although the present study was a first step (i.e., feasibility study) in rigorous treatment studies for compulsive sexual behaviors and PPU (Griffin et al., 2021; Grubbs et al., 2020; Grubbs \& Kraus, 2021; Rounsaville et al., 2001), findings are promising that online 
interventions for PPU might help reduce PPU in some cases, reducing treatment barriers.

Funding: The research was supported by the Hungarian National Research, Development, and Innovation Office (Grant numbers: KKP126835, NKFIH-1157-8/2019-DT, K134807). BB was supported by the ÚNKP-18-3 New National Excellence Program of the Ministry of Human Capacities to develop the intervention protocol. BB was supported by the Merit Scholarship Program for Foreign Students (PBEEE) awarded by the Ministere de l'Éducation et de l'Enseignement Supérieur (MEES) and by a postdoctoral fellowship from the SCOUP Team - Sexuality and Couples - Fonds de recherche du Québec, Société et Culture during the finalization of the paper.

Authors' contribution: $\mathrm{BB}, \mathrm{CB}, \mathrm{MPS}, \mathrm{ZD}$, and GO set up the initial idea and plan for this study. BB and CB prepared the first draft of the paper and $\mathrm{BB}$ finished the final manuscript. $\mathrm{BB}$ and GO developed the intervention of study arm 1 . $\mathrm{CB}$, MPS, and ZD helped throughout the development of the intervention. $\mathrm{CB}$ programmed and implemented the intervention website. CB performed statistical analysis. GO, MPS, and $\mathrm{ZD}$ and gave valuable feedback to the study. All authors approved the final version of the manuscript submitted for publication. $\mathrm{BB}$ is the guarantor.

Conflict of interest: The authors declare no conflict of interest.

Pre-registration: The study was preregistered on the Open Science Framework (OSF) Website: https://osf.io/5tqkb/

Acknowledgments: We would like to thank László Naske and Ivett Lénárt for creating the design and the graphics of the program. We would also like to thank all participants for taking the time and efforts to participate in the intervention and provide valuable feedback.

\section{REFERENCES}

Altman, D. (2014). The mindfulness toolbox: 50 practical tips, tools \& handouts for anxiety, depression, stress \& pain. PESI Publishing \& Media.

Amann, M., Haug, S., Wenger, A., Baumgartner, C., Ebert, D. D., Berger, T., ... Schaub, M. P. (2018). The effects of social presence on adherence-focused guidance in problematic cannabis users: Protocol for the CANreduce 2.0 randomized controlled trial. JMIR Research Protocols, 7(1), e30. https://doi. org/10.2196/resprot.9484.

Arain, M., Campbell, M. J., Cooper, C. L., \& Lancaster, G. A. (2010). What is a pilot or feasibility study? A review of current practice and editorial policy. BMC Medical Research Methodology, 10, 1-7. https://doi.org/10.1186/1471-2288-10-67.

Asner-Self, K. K., Schreiber, J. B., \& Marotta, S. A. (2006). A crosscultural analysis of the Brief Symptom inventory-18. Cultural
Diversity and Ethnic Minority Psychology, 12(2), 367-375. https://doi.org/10.1037/1099-9809.12.2.367.

Baumgartner, C., Bilevicius, E., Khazaal, Y., Achab, S., Schaaf, S., Wenger, A., ... Schaub, M. P. (2019). Efficacy of a web-based self-help tool to reduce problem gambling in Switzerland: Study protocol of a two-armed randomised controlled trial. BMJ Open, 9(12), 1-11. https://doi.org/10.1136/bmjopen-2019032110.

Baumgartner, C., Schaub, M. P., Wenger, A., Malischnig, D., Augsburger, M., Walter, M., ... Haug, S. (2021). CANreduce 2.0 adherence-focused guidance for internet self-help among cannabis users: Three-arm randomized controlled trial. Journal of Medical Internet Research, 23(4), e27463. https://doi.org/10. 2196/27463.

Becker, J., Haug, S., Sullivan, R., \& Schaub, M. P. (2014). Effectiveness of different web-based interventions to prepare cosmokers of cigarettes and cannabis for double cessation: A three-arm randomized controlled trial. Journal of Medical Internet Research, 16(12), e3246. https://doi.org/10.2196/JMIR. 3246.

Beintner, I., Emmerich, O. L. M., Vollert, B., Taylor, C. B., \& Jacobi, C. (2019). Promoting positive body image and intuitive eating in women with overweight and obesity via an online intervention: Results from a pilot feasibility study. Eating Behaviors, 34(January). https://doi.org/10.1016/j.eatbeh.2019.101307.

Bowen, D. J., Kreuter, M., Spring, B., Cofta-Woerpel, L., Linnan, L., Weiner, D., ... Fernandez, M. (2009). How we design feasibility studies. American Journal of Preventive Medicine, 36(5), 452457. https://doi.org/10.1016/j.amepre.2009.02.002.

Bőthe, B., Bartók, R., Tóth-Király, I., Reid, R. C., Griffiths, M. D., Demetrovics, Z., \& Orosz, G. (2018). Hypersexuality, gender, and sexual orientation: A large-scale psychometric survey study. Archives of Sexual Behavior, 47(8), 2265-2276. https:// doi.org/10.1007/s10508-018-1201-z.

Bőthe, B., Baumgartner, C., Schaub, M. P., Demetrovics, Z., \& Orosz, G. (2020). Hands-off: Study protocol of a two-armed randomized controlled trial of a web-based self-help tool to reduce problematic pornography use. Journal of Behavioral Addictions, 9(2), 433-445. https://doi.org/10.1556/2006.2020. 00037.

Bőthe, B., Lonza, A., Štulhofer, A., \& Demetrovics, Z. (2020). Symptoms of problematic pornography use in a sample of treatment considering and treatment non-considering men: A network approach. Journal of Sexual Medicine, 17(10), 20162028. https://doi.org/10.1016/j.jsxm.2020.05.030.

Bőthe, B., Tóth-Király, I., Demetrovics, Z., \& Orosz, G. (2017). The pervasive role of sex mindset: Beliefs about the malleability of sexual life is linked to higher levels of relationship satisfaction and sexual satisfaction and lower levels of problematic pornography use. Personality and Individual Differences, 117, 15-22. https://doi.org/10.1016/j.paid.2017.05.030.

Bőthe, B., Tóth-Király, I., Demetrovics, Z., \& Orosz, G. (2021). The short version of the problematic pornography consumption scale (PPCS-6): A reliable and valid measure in general and treatment-seeking populations. Journal of Sex Research, 58(3), 342-352. https://doi.org/10.1080/00224499.2020.1716205.

Bőthe, B., Tóth-Király, I., Griffiths, M. D., Potenza, M. N., Orosz, G., \& Demetrovics, Z. (2021). Are sexual functioning problems 
associated with frequent pornography use and/or problematic pornography use? Results from a large community survey including males and females. Addictive Behaviors, 112, 1-9. https://doi.org/10.1016/j.addbeh.2020.106603.

Bőthe, B., Tóth-Király, I., Potenza, M. N., Orosz, G., \& Demetrovics, Z. (2020). High-frequency pornography use may not always be problematic. Journal of Sexual Medicine, 17(4), 793811. https://doi.org/10.1016/j.jsxm.2020.01.007.

Bőthe, B., Tóth-Király, I., Zsila, Á., Griffiths, M. D., Demetrovics, Z., \& Orosz, G. (2018). The development of the problematic pornography consumption scale (PPCS). Journal of Sex Research, 55(3), 395-406. https://doi.org/10.1080/00224499.2017.1291798.

Bőthe, B., Vaillancourt-Morel, M.-P., Dion, J., Štulhofer, A., \& Bergeron, S. (2021). Validity and reliability of the short version of the problematic pornography consumption scale (PPCS-6-A) in adolescents. Psychology of Addictive Behaviors, 35(4), 486500 .

Bőthe, B., Vaillancourt-Morel, M.-P., Girouard, A., Štulhofer, A., Dion, J., \& Bergeron, S. (2020). A large-scale comparison of Canadian sexual/gender minority and heterosexual, cisgender adolescents' pornography use characteristics. Journal of Sexual Medicine, 17(6), 1156-1167. https://doi.org/10.1016/j.jsxm. 2020.02.009.

Chen, L., Jiang, X., Luo, X., Kraus, S. W., \& Böthe, B. (2021).The role of impaired control in screening problematic pornography use: Evidence from cross-sectional and longitudinal studies in a large help-seeking male sample. Psychology of Addictive Behaviors. https://doi.org/10.1037/adb0000714.

Crosby, J. M. (2011). Acceptance and commitment therapy for the treatment of compulsive pornography use: A randomized clinical trial. Utah State University.

Crosby, J. M., \& Twohig, M. P. (2016). Acceptance and commitment therapy for problematic internet pornography use: A randomized trial. Behavior Therapy, 47(3), 355-366. https://doi. org/10.1016/j.beth.2016.02.001.

Dhuffar, M. K., \& Griffiths, M. D. (2015). A systematic review of online sex addiction and clinical treatments using CONSORT evaluation. Current Addiction Reports, 2(2), 163-174. https:// doi.org/10.1007/s40429-015-0055-x.

Dhuffar, M. K., \& Griffiths, M. D. (2016). Barriers to female sex addiction treatment in the UK. Journal of Behavioral Addictions, 5(4), 562-567. https://doi.org/10.1556/2006.5.2016.072.

Diener, E., Emmons, R. A., Larsen, R. J., \& Griffin, S. (1985). The satisfaction with life scale. Journal of Personality Assessment, 49(1), 71-75. https://doi.org/10.1207/s15327752jpa4901_13.

Dube, P., Kroenke, K., Bair, M. J., Theobald, D., \& Williams, L. S. (2010). P4 suicidality screener. Prim Care Companion J Clin Psychiatry, 12(6), 6-7.

Efrati, Y., \& Gola, M. (2018). Treating compulsive sexual behavior. Current Sexual Health Reports, 10(2), 57-64. https://doi.org/10. 1007/s11930-018-0143-8.

Fernandez, D. P., \& Griffiths, M. D. (2019). Psychometric instruments for problematic pornography use: A systematic review. Evaluation and the Health Professions, 1-71. https://doi. org/10.1177/0163278719861688.

von Franqué, F., Klein, V., \& Briken, P. (2015). Which techniques are used in psychotherapeutic interventions for nonparaphilic hypersexual behavior? Sexual Medicine Reviews, 3(1), 3-10. https://doi.org/10.1002/smrj.34.

Gola, M., Lewczuk, K., \& Skorko, M. (2016). What matters: Quantity or quality of pornography use? Psychological and behavioral factors of seeking treatment for problematic pornography use. Journal of Sexual Medicine, 13(5), 815-824. https://doi.org/10.1016/j.jsxm.2016.02.169.

Gottlieb, L. D., Horwitz, R. I., Kraus, M. L., Segal, S. R., \& Viscoli, C. M. (1994). Randomized controlled trial in alcohol relapse prevention: Role of atenolol, alcohol craving, and treatment adherence. Journal of Substance Abuse Treatment, 11(3), 253258. https://doi.org/10.1016/0740-5472(94)90083-3.

Griffin, K. R., Way, B. M., \& Kraus, S. W. (2021). Controversies and clinical recommendations for the treatment of compulsive sexual behavior disorder. Current Addiction Reports, 0123456789. https://doi.org/10.1007/s40429-021-00393-5.

Group, W. A. W. (2002). The alcohol, smoking and substance involvement screening test (ASSIST): Development, reliability and feasibility. Addiction, 97(9), 1183-1194. https://doi.org/10. 1046/j.1360-0443.2002.00185.x.

Grubbs, J. B., Hoagland, C., Lee, B., Grant, J., Davison, P. M., Reid, R., \& Kraus, S. W. (2020). Sexual addiction 25 years on: A systematic and methodological review of empirical literature and an agenda for future research. Clinical Psychology Review, 1-15. https://doi.org/10.1016/j.cpr.2020.101925.

Grubbs, J. B., \& Kraus, S. W. (2021). Pornography use and psychological science: A call for consideration. Current Directions in Psychological Science, 1-8. http://journals.sagepub.com/doi/ 10.1177/0963721420979594.

Grubbs, J. B., Kraus, S. W., \& Perry, S. L. (2019). Self-reported addiction to pornography in a nationally representative sample: The roles of use habits, religiousness, and moral incongruence. Journal of Behavioral Addictions, 8(1), 88-93. https://doi.org/ 10.1556/2006.7.2018.134.

Grubbs, J. B., \& Perry, S. L. (2019). Moral incongruence and pornography use: A critical review and integration. Journal of Sex Research, 56(1), 29-37. https://doi.org/10.1080/00224499. 2018.1427204.

Grubbs, J. B., Perry, S. L., Wilt, J. A., \& Reid, R. C. (2019). Pornography problems due to moral incongruence: An integrative model with a systematic review and meta-analysis. Archives of Sexual Behavior, 48(2), 397-415. https://doi.org/10. 1007/s10508-018-1248-x.

Gyollai, Á., Simor, P., Köteles, F., \& Demetrovics, Z. (2011). Psychometric properties of the Hungarian version of the original and the short form of the Positive and Negative Affect Schedule (PANAS). Neuropsychopharmacologia Hungarica, 13(2), 73-79.

Haug, S., Castro, R. P., Wenger, A., \& Schaub, M. P. (2018). Efficacy of a mobile phone-based life-skills training program for substance use prevention among adolescents: Study protocol of a cluster-randomised controlled trial. BMC Public Health, 18(1102), 1-9. https://doi.org/10.1186/s12889-018-5969-5.

Herbenick, D., Fu, T.-C., Wright, P., Paul, B., Gradus, R., Bauer, J., \& Jones, R. (2020). Diverse sexual behaviors and pornography use: Findings from a nationally representative probability survey of Americans aged 14 to 60 years. Journal of Sexual Medicine, 1-11. https://doi.org/10.1016/j.jsxm.2020.01.013. 
Herrero, R., Mira, A., Cormo, G., Etchemendy, E., Baños, R., García-Palacios, A., ... Botella, C. (2019). An Internet based intervention for improving resilience and coping strategies in university students: Study protocol for a randomized controlled trial. Internet Interventions, 16, 43-51. https://doi.org/10.1016/j. invent.2018.03.005.

Kafka, M. P. (2010). Hypersexual disorder: A proposed diagnosis for DSM-V. Archives of Sexual Behavior, 39(2), 377-400. https://doi.org/10.1007/s10508-009-9574-7.

Klein, V., Savaş, Ö., \& Conley, T. D. (2021). How WEIRD and androcentric is sex research? Global inequities in study populations. Journal of Sex Research, 1-8. https://doi.org/10.1080/ 00224499.2021.1918050.

Kraus, S. W., Krueger, R. B., Briken, P., First, M. B., Stein, D. J., Kaplan, M. S., ... Reed, G. M. (2018). Compulsive sexual behaviour disorder in the ICD-11. World Psychiatry, 17(1), 109-110. https://doi.org/10.1002/wps.20499.

Kraus, S. W., Martino, S., \& Potenza, M. N. (2016). Clinical characteristics of men interested in seeking treatment for use of pornography. Journal of Behavioral Addictions, 5(2), 169-178. https://doi.org/10.1556/2006.5.2016.036.

Kraus, S. W., \& Rosenberg, H. (2014). The pornography craving questionnaire: Psychometric properties. Archives of Sexual Behavior, 43(3), 451-462. https://doi.org/10.1007/s10508-0130229-3.

Kraus, S. W., Rosenberg, H., Martino, S., Nich, C., \& Potenza, M. N. (2017). The development and initial evaluation of the pornography-use avoidance self-efficacy scale. Journal of Behavioral Addictions, 6(3), 354-363. https://doi.org/10.1556/ 2006.6.2017.057.

Kraus, S. W., \& Sweeney, P. J. (2019). Hitting the target: Considerations for differential diagnosis when treating individuals for problematic use of pornography. Archives of Sexual Behavior, 48(2), 431-435. https://doi.org/10.1007/s10508-018-1301-9.

Lewczuk, K., Glica, A., Nowakowska, I., Gola, M., \& Grubbs, J. B. (2020). Evaluating pornography problems due to moral incongruence model. Journal of Sexual Medicine, 17(2), 300311. https://doi.org/10.1016/j.jsxm.2019.11.259.

Lewczuk, K., Szmyd, J., Skorko, M., \& Gola, M. (2017). Treatment seeking for problematic pornography use among women. Journal of Behavioral Addictions, 6(4), 445-456. https://doi.org/ 10.1556/2006.6.2017.063.

Mark, K. P., Herbenick, D., Fortenberry, J. D., Sanders, S., \& Reece, M. (2014). A psychometric comparison of three scales and a single-item measure to assess sexual satisfaction. Journal of Sex Research, 51(2), 159-169. https://doi.org/10.1080/00224499. 2013.816261.

Meichenbaum, D. (1977). Cognitive behaviour modification. Scandinavian Journal of Behaviour Therapy, 6(4), 185-192. https://doi.org/10.1080/16506073.1977.9626708.

Miller, W. R., Tonigan, J. S., \& Longabaugh, R. (1995). The drinker inventory of consequences (Project MATCH monograph No. 4). US Department of Health and Human Services.

Minarcik, J. (2016). Proposed treatment of problematic pornography use: A cognitive-behavioral approach. University of Arkansas.

Orsmond, G. I., \& Cohn, E. S. (2015). The distinctive features of a feasibility study: Objectives and guiding questions. OTJR
Occupation, Participation and Health, 35(3), 169-177. https:// doi.org/10.1177/1539449215578649.

Panlilio, L. V., Stull, S. W., Kowalczyk, W. J., Phillips, K. A., Schroeder, J. R., Bertz, J. W., ... Preston, K. L. (2019). Stress, craving and mood as predictors of early dropout from opioid agonist therapy. Drug and Alcohol Dependence, 202, 200-208. https://doi.org/10.1016/j.drugalcdep.2019.05.026.

R Core Team (2019). R: A language and environment for statistical computing (3.6.1).

Rissel, C., Richters, J., de Visser, R. O., McKee, A., Yeung, A., \& Caruana, T. (2017). A profile of pornography users in Australia: Findings from the second Australian study of health and relationships. Journal of Sex Research, 54(2), 227-240. https://doi. org/10.1080/00224499.2016.1191597.

Rollnick, S., \& Miller, W. R. (1995). What is motivational interviewing? Behavioural and Cognitive Psychotherapy, 23(4), 325334. https://doi.org/10.1017/S135246580001643X.

Rooke, S., Copeland, J., Norberg, M., Hine, D., \& McCambridge, J. (2013). Effectiveness of a self-guided web-based cannabis treatment program: Randomized controlled trial. Journal of Medical Internet Research, 15(2), e26. https://doi.org/10.2196/ jmir.2256.

Rounsaville, B. J., Carroll, K. M., \& Onken, L. S. (2001). A stage model of behavioral therapies research: Getting started and moving on from stage I. Clinical Psychology: Science and Practice, 73(4), 133-142. https://doi.org/10.1093/clipsy/8.2.133.

Schaub, M. P., Blankers, M., Lehr, D., Boss, L., Riper, H., Dekker, J., ... Ebert, D. D. (2016). Efficacy of an internet-based self-help intervention to reduce co-occurring alcohol misuse and depression symptoms in adults: Study protocol of a three-arm randomised controlled trial. BMJ Open, 6(5), e011457. https:// doi.org/10.1136/bmjopen-2016-011457.

Schaub, M. P., Haug, S., Wenger, A., Berg, O., Sullivan, R., Beck, T., \& Stark, L. (2013). Can reduce - the effects of chat-counseling and web-based self-help, web-based self-help alone and a waiting list control program on cannabis use in problematic cannabis users: A randomized controlled trial. BMC Psychiatry, 13(1), 305. https://doi.org/10.1186/1471-244X-13-305.

Schaub, M. P., Wenger, A., Berg, O., Beck, T., Stark, L., Buehler, E., \& Haug, S. (2015). A web-based self-help intervention with and without chat counseling to reduce cannabis use in problematic cannabis users: Three-arm randomized controlled trial. Journal of Medical Internet Research, 17(10), e232. https://doi.org/10. 2196/jmir.4860.

Sniewski, L., \& Farvid, P. (2020). Hidden in shame: Heterosexual men's experiences of self-perceived problematic pornography use. Psychology of Men and Masculinity, 21(2), 201-212. https:// doi.org/10.1037/men0000232.

Ustun, B., Adler, L. A., Rudin, C., Faraone, S. V., Spencer, T. J., Berglund, P., ... Kessler, R. C. (2017). The world health organization adult attention-deficit/hyperactivity disorder selfreport screening scale for DSM-5. JAMA Psychiatry, 74(5), 520526. https://doi.org/10.1001/jamapsychiatry.2017.0298.

Vaillancourt-Morel, M.-P. P., Blais-Lecours, S., Labadie, C., Bergeron, S., Sabourin, S., \& Godbout, N. (2017). Profiles of cyberpornography use and sexual well-being in adults. Journal of Sexual Medicine, 14(1), 78-85. https://doi.org/10.1016/j.jsxm.2016.10.016. 
Walton, G. M. (2014). The new science of wise psychological interventions. Current Directions in Psychological Science, 23(1), 73-82. https://doi.org/10.1177/0963721413512856.

Walton, G. M., \& Wilson, T. D. (2018). Wise interventions: Psychological remedies for social and personal problems. Psychological Review, 125(5), 617-655. https://doi.org/10.1037/ rev0000115.

Weisel, K., Lehr, D., Heber, E., Zarski, A. C., Berking, M., Riper, H., \& Ebert, D. D. (2018). Severely burdened individuals do not need to be excluded from internet-based and mobile-based stress management: Effect modifiers of treatment outcomes from three randomized controlled trials. Journal of Medical Internet Research, 20(6), 1-16. https://doi.org/10.2196/jmir. 9387.

Weisel, K., Zarski, A.-C., Berger, T., Krieger, T., Schaub, M. P., Moser, C. T., ... Ebert, D. D. (2019). Efficacy and cost-effectiveness of guided and unguided internet- and mobile-based indicated transdiagnostic prevention of depression and anxiety (ICare prevent): A three-armed randomized controlled trial in four European countries. Internet Interventions, 16, 52-64. https://doi.org/10.1016/J.INVENT.2018.04.002.

Werner, M., Štulhofer, A., Waldorp, L., \& Jurin, T. (2018). A network approach to hypersexuality: Insights and clinical implications. Journal of Sexual Medicine, 15(3), 410-415. https://doi.org/10.1016/j.jsxm.2018.01.009.

Wéry, A., \& Billieux, J. (2017). Problematic cybersex: Conceptualization, assessment, and treatment. Addictive Behaviors, 64, 238-246. https://doi.org/10.1016/j.addbeh.2015.11.007.

World Health Organization (2019). International statistical classification of diseases and related health problems (11th ed.). https://icd.who.int/.

Wright, P. J., Herbenick, D., \& Paul, B. (2019). Adolescent condom use, parent-adolescent sexual health communication, and pornography: Findings from a U.S. Probability sample. Journal of Health Communication, 0236(13). https://doi.org/10.1080/ 10410236.2019.1652392.

Yeager, D. S., \& Walton, G. M. (2011). Social-psychological interventions in education: They're not magic. Review of Educational Research, 81(2), 267-301. https://doi.org/10.3102/ 0034654311405999.

Zarski, A. C., Lehr, D., Berking, M., Riper, H., Cuijpers, P., \& Ebert, D. D. (2016). Adherence to internet-based mobile-supported stress management: A pooled analysis of individual participant data from three randomized controlled trials. Journal of Medical Internet Research, 18(6), e4493. https://doi.org/10.2196/ jmir.4493.

\section{APPENDIX 1}

Appendix 1. Consort 2010 checklist of information to include when reporting a randomised trial*

\begin{tabular}{|c|c|c|c|}
\hline Section/Topic & Item No & Checklist item & Reported on page No \\
\hline \multicolumn{4}{|l|}{ Title and abstract } \\
\hline & 1a & $\begin{array}{l}\text { Identification as a randomised trial in } \\
\text { the title }\end{array}$ & 1 \\
\hline & $1 \mathrm{~b}$ & $\begin{array}{l}\text { Structured summary of trial design, } \\
\text { methods, results, and conclusions (for } \\
\text { specific guidance see CONSORT for } \\
\text { abstracts) }\end{array}$ & 1 \\
\hline \multicolumn{4}{|l|}{ Introduction } \\
\hline \multirow[t]{2}{*}{ Background and objectives } & $2 \mathrm{a}$ & $\begin{array}{c}\text { Scientific background and explanation } \\
\text { of rationale }\end{array}$ & 2 \\
\hline & $2 \mathrm{~b}$ & Specific objectives or hypotheses & 2 \\
\hline \multicolumn{4}{|l|}{ Methods } \\
\hline \multirow[t]{2}{*}{ Trial design } & $3 a$ & $\begin{array}{c}\text { Description of trial design (such as } \\
\text { parallel, factorial) including allocation } \\
\text { ratio }\end{array}$ & $3-5$ \\
\hline & $3 b$ & $\begin{array}{l}\text { Important changes to methods after } \\
\text { trial commencement (such as eligibility } \\
\text { criteria), with reasons }\end{array}$ & NA \\
\hline \multirow[t]{2}{*}{ Participants } & $4 a$ & Eligibility criteria for participants & 3 \\
\hline & $4 \mathrm{~b}$ & $\begin{array}{l}\text { Settings and locations where the data } \\
\text { were collected }\end{array}$ & 3 \\
\hline Interventions & 5 & $\begin{array}{l}\text { The interventions for each group with } \\
\text { sufficient details to allow replication, } \\
\text { including how and when they were } \\
\text { actually administered }\end{array}$ & $3-5$ \\
\hline Outcomes & $6 a$ & $\begin{array}{l}\text { Completely defined pre-specified } \\
\text { primary and secondary outcome }\end{array}$ & $5-6$ \\
\hline
\end{tabular}




\section{Appendix 1. Continued}

\begin{tabular}{|c|c|c|c|}
\hline Section/Topic & Item No & Checklist item & Reported on page No \\
\hline & & $\begin{array}{l}\text { measures, including how and when they } \\
\text { were assessed }\end{array}$ & \\
\hline & $6 \mathrm{~b}$ & $\begin{array}{l}\text { Any changes to trial outcomes after the } \\
\text { trial commenced, with reasons }\end{array}$ & 2,6 \\
\hline \multirow[t]{2}{*}{ Sample size } & $7 \mathrm{a}$ & How sample size was determined & 3 \\
\hline & $7 \mathrm{~b}$ & $\begin{array}{c}\text { When applicable, explanation of any } \\
\text { interim analyses and stopping } \\
\text { guidelines }\end{array}$ & NA \\
\hline \multicolumn{4}{|l|}{ Randomisation: } \\
\hline \multirow[t]{2}{*}{ Sequence generation } & $8 \mathrm{a}$ & $\begin{array}{l}\text { Method used to generate the random } \\
\text { allocation sequence }\end{array}$ & 3 \\
\hline & $8 b$ & $\begin{array}{l}\text { Type of randomisation; details of any } \\
\text { restriction (such as blocking and block } \\
\text { size) }\end{array}$ & 3 \\
\hline Allocation concealment mechanism & 9 & $\begin{array}{l}\text { Mechanism used to implement the } \\
\text { random allocation sequence (such as } \\
\text { sequentially numbered containers), } \\
\text { describing any steps taken to conceal } \\
\text { the sequence until interventions were } \\
\text { assigned }\end{array}$ & 3 \\
\hline Implementation & 10 & $\begin{array}{l}\text { Who generated the random allocation } \\
\text { sequence, who enrolled participants, } \\
\text { and who assigned participants to } \\
\text { interventions }\end{array}$ & 3 \\
\hline \multirow[t]{2}{*}{ Blinding } & $11 \mathrm{a}$ & $\begin{array}{l}\text { If done, who was blinded after } \\
\text { assignment to interventions (for } \\
\text { example, participants, care providers, } \\
\text { those assessing outcomes) and how }\end{array}$ & 3 \\
\hline & $11 b$ & $\begin{array}{l}\text { If relevant, description of the similarity } \\
\text { of interventions }\end{array}$ & NA \\
\hline \multirow[t]{2}{*}{ Statistical methods } & $12 \mathrm{a}$ & $\begin{array}{c}\text { Statistical methods used to compare } \\
\text { groups for primary and secondary } \\
\text { outcomes }\end{array}$ & 6 \\
\hline & $12 \mathrm{~b}$ & $\begin{array}{c}\text { Methods for additional analyses, such as } \\
\text { subgroup analyses and adjusted } \\
\text { analyses }\end{array}$ & 6 \\
\hline \multicolumn{4}{|l|}{ Results } \\
\hline \multirow[t]{2}{*}{$\begin{array}{l}\text { Participant flow (a diagram is strongly } \\
\text { recommended) }\end{array}$} & $13 \mathrm{a}$ & $\begin{array}{c}\text { For each group, the numbers of } \\
\text { participants who were randomly } \\
\text { assigned, received intended treatment, } \\
\text { and were analysed for the primary } \\
\text { outcome }\end{array}$ & $3-6$ \\
\hline & $13 b$ & $\begin{array}{l}\text { For each group, losses and exclusions } \\
\text { after randomisation, together with } \\
\text { reasons }\end{array}$ & 3 \\
\hline \multirow[t]{2}{*}{ Recruitment } & $14 \mathrm{a}$ & $\begin{array}{l}\text { Dates defining the periods of } \\
\text { recruitment and follow-up }\end{array}$ & 3 \\
\hline & $14 \mathrm{~b}$ & Why the trial ended or was stopped & 3 \\
\hline Baseline data & 15 & $\begin{array}{l}\text { A table showing baseline demographic } \\
\text { and clinical characteristics for each } \\
\text { group }\end{array}$ & $4-5$ \\
\hline Numbers analysed & 16 & $\begin{array}{c}\text { For each group, number of participants } \\
\text { (denominator) included in each analysis } \\
\text { and whether the analysis was by original } \\
\text { assigned groups }\end{array}$ & 8 \\
\hline Outcomes and estimation & $17 \mathrm{a}$ & $\begin{array}{l}\text { For each primary and secondary } \\
\text { outcome, results for each group, and the }\end{array}$ & $7-8$ \\
\hline
\end{tabular}

(continued) 
Appendix 1. Continued

\begin{tabular}{|c|c|c|c|}
\hline Section/Topic & Item No & Checklist item & Reported on page No \\
\hline & & $\begin{array}{l}\text { estimated effect size and its precision } \\
\text { (such as } 95 \% \text { confidence interval) }\end{array}$ & \\
\hline & $17 \mathrm{~b}$ & $\begin{array}{l}\text { For binary outcomes, presentation of } \\
\text { both absolute and relative effect sizes is } \\
\text { recommended }\end{array}$ & NA \\
\hline Ancillary analyses & 18 & $\begin{array}{l}\text { Results of any other analyses } \\
\text { performed, including subgroup analyses } \\
\text { and adjusted analyses, distinguishing } \\
\text { pre-specified from exploratory }\end{array}$ & $7-11,19-21$ \\
\hline Harms & 19 & $\begin{array}{l}\text { All important harms or unintended } \\
\text { effects in each group (for specific } \\
\text { guidance see CONSORT for harms) }\end{array}$ & NA \\
\hline \multicolumn{4}{|l|}{ Discussion } \\
\hline Limitations & 20 & $\begin{array}{l}\text { Trial limitations, addressing sources of } \\
\text { potential bias, imprecision, and, if } \\
\text { relevant, multiplicity of analyses }\end{array}$ & 13 \\
\hline Generalisability & 21 & $\begin{array}{l}\text { Generalisability (external validity, } \\
\text { applicability) of the trial findings }\end{array}$ & $11-13$ \\
\hline Interpretation & 22 & $\begin{array}{l}\text { Interpretation consistent with results, } \\
\text { balancing benefits and harms, and } \\
\text { considering other relevant evidence }\end{array}$ & $11-13$ \\
\hline \multicolumn{4}{|l|}{ Other information } \\
\hline Registration & 23 & $\begin{array}{c}\text { Registration number and name of trial } \\
\text { registry }\end{array}$ & 14 \\
\hline Protocol & 24 & $\begin{array}{l}\text { Where the full trial protocol can be } \\
\text { accessed, if available }\end{array}$ & 3,14 \\
\hline Funding & 25 & $\begin{array}{l}\text { Sources of funding and other support } \\
\text { (such as supply of drugs), role of } \\
\text { funders }\end{array}$ & 14 \\
\hline
\end{tabular}

*We strongly recommend reading this statement in conjunction with the CONSORT 2010 Explanation and Elaboration for important clarifications on all the items. If relevant, we also recommend reading CONSORT extensions for cluster randomised trials, non-inferiority and equivalence trials, non-pharmacological treatments, herbal interventions, and pragmatic trials. Additional extensions are forthcoming: for those and for up to date references relevant to this checklist, see www.consort-statement.org.

\section{APPENDIX 2}

Table A1. Baseline sociodemographic, pornography use-related, and psychological characteristics of participants in the intervention group who did not complete any modules, completed only one module, and completed more than one module

\begin{tabular}{|c|c|c|c|c|}
\hline & $\begin{array}{l}\text { Did not complete any } \\
\text { moules }(n=41)\end{array}$ & $\begin{array}{l}\text { Completed only one } \\
\text { module }(n=37)\end{array}$ & $\begin{array}{l}\text { Completed more than } \\
\text { one module }(n=45)\end{array}$ & $\begin{array}{c}\text { Statistical Analysis (Chi- } \\
\text { Square Test, ANOVA) }\end{array}$ \\
\hline \multicolumn{5}{|l|}{ Gender, $n(\%)$} \\
\hline Woman & $4(9.8)$ & $0(0)$ & $1(2.2)$ & $N A$ \\
\hline Man & $37(90.2)$ & $37(100.0)$ & $44(97.8)$ & \\
\hline Age, $M(S D)$ & $35.4(11.7)$ & $28.4(8.8)$ & $35.4(12.2)$ & $\begin{array}{c}F(2,120)=5.14 \\
P=0.007\end{array}$ \\
\hline Highest education, $n(\%)$ & & & & $\begin{aligned} \chi^{2}(2, N & =123)=3.28 \\
P & =0.194\end{aligned}$ \\
\hline Primary school & $0(0.0)$ & $0(0.0)$ & $0(0.0)$ & \\
\hline Vocational school & $1(2.4)$ & $1(2.7)$ & $0(0.0)$ & \\
\hline High school & $12(29.3)$ & $7(18.9)$ & $7(15.6)$ & \\
\hline College or university & $28(68.3)$ & $29(78.4)$ & $38(84.4)$ & \\
\hline Country of origin, $n(\%)$ & & & & $\begin{aligned} \chi^{2}(10, N & =123) \\
=10.11, P & =0.431\end{aligned}$ \\
\hline
\end{tabular}

(continued) 
Table A1. Continued

\begin{tabular}{|c|c|c|c|c|}
\hline & $\begin{array}{l}\text { Did not complete any } \\
\text { moules }(n=41)\end{array}$ & $\begin{array}{l}\text { Completed only one } \\
\text { module }(n=37)\end{array}$ & $\begin{array}{l}\text { Completed more than } \\
\text { one module }(n=45)\end{array}$ & $\begin{array}{l}\text { Statistical Analysis (Chi- } \\
\text { Square Test, ANOVA) }\end{array}$ \\
\hline United States & $13(31.7)$ & $13(35.1)$ & $17(37.8)$ & \\
\hline England & $6(14.6)$ & $5(13.5)$ & $8(17.8)$ & \\
\hline Canada & $5(12.2)$ & $2(5.4)$ & $5(11.1)$ & \\
\hline Hungary & $5(12.2)$ & $3(8.1)$ & $2(4.4)$ & \\
\hline India & $0(0.0)$ & $3(8.1)$ & $0(0.0)$ & \\
\hline Other $\left(\right.$ combined $\left.^{\mathrm{a}}\right)$ & $12(29.3)$ & $11(29.7)$ & $13(28.9)$ & \\
\hline Relationship status, $n$ (\%) & & & & $\begin{aligned} & \chi^{2}(8, N=123) \\
= & 14.94, P=0.060\end{aligned}$ \\
\hline Single & $15(36.6)$ & $17(45.9)$ & $11(24.4)$ & \\
\hline In a relationship & $12(29.3)$ & $16(43.2)$ & $12(26.7)$ & \\
\hline Married & $13(31.7)$ & $4(10.8)$ & $20(44.4)$ & \\
\hline Engaged & $1(2.4)$ & $0(0.0)$ & $1(2.2)$ & \\
\hline Other & $0(0.0)$ & $0(0.0)$ & $1(0.0)$ & \\
\hline Sexual orientation, $n(\%)$ & & & & $\begin{aligned} \chi^{2}(6, N & =123)=5.54, \\
P & =0.477\end{aligned}$ \\
\hline Heterosexual & $31(75.6)$ & $27(73.0)$ & $34(75.6)$ & \\
\hline Homosexual & $1(2.4)$ & $4(10.8)$ & $2(4.4)$ & \\
\hline Bisexual & $6(14.6)$ & $3(8.1)$ & $8(17.8)$ & \\
\hline Unsure & $3(7.3)$ & $3(8.1)$ & $1(2.2)$ & \\
\hline $\begin{array}{l}\text { Sought treatment for } \\
\text { pornography use previously, } \\
n(\%)\end{array}$ & $13(31.7)$ & $12(32.4)$ & $15(33.3)$ & $\begin{aligned} \chi^{2}(2, N & =123)=0.02 \\
P & =0.987\end{aligned}$ \\
\hline $\begin{array}{l}\text { Problematic pornography use } \\
\quad \text { (Range 0-126), } M(S D)\end{array}$ & $76.5(19.8)$ & $82.5(13.7)$ & $82.4(15.4)$ & $\begin{array}{c}F(2,120)=1.74 \\
P=0.180\end{array}$ \\
\hline $\begin{array}{l}\text { Pornography use frequency, } \\
n(\%)\end{array}$ & & & & $\begin{aligned} \chi^{2}(2, N & =123)=1.23, \\
P & =0.541\end{aligned}$ \\
\hline$>7$ a week & $14(34.1)$ & $9(24.3)$ & $12(26.7)$ & \\
\hline 6-7 a week & $7(17.1)$ & $7(18.9)$ & $7(15.6)$ & \\
\hline $4-5$ a week & $8(19.5)$ & $7(18.9)$ & $7(15.6)$ & \\
\hline 2-3 a week & $5(12.2)$ & $6(16.2)$ & $8(17.8)$ & \\
\hline weekly & $2(4.9)$ & $3(8.1)$ & $6(13.3)$ & \\
\hline Less frequently & $5(12.2)$ & $5(13.5)$ & $5(11.1)$ & \\
\hline $\begin{array}{l}\text { Time spent with pornography } \\
\text { use per session in minutes, } M \\
\text { (SD) }\end{array}$ & $46.9(44.1)$ & $47.4(35.9)$ & $57.7(57.8)$ & $\begin{array}{c}F(2,120)=0.70 \\
P=0.499\end{array}$ \\
\hline $\begin{array}{l}\text { Moral incongruence concerning } \\
\text { pornography use (Range 0- } \\
\text { 6), M (SD) }\end{array}$ & $2.7(1.9)$ & $3.2(2.2)$ & $3.2(2.2)$ & $\begin{array}{c}F(2,120)=0.81 \\
P=0.447\end{array}$ \\
\hline $\begin{array}{l}\text { Self-perceived pornography } \\
\text { addiction (Range 0-6), } \\
M(S D)\end{array}$ & $4.5(1.7)$ & $4.7(1.5)$ & $4.7(1.2)$ & $\begin{array}{c}F(2,120)=0.42 \\
P=0.656\end{array}$ \\
\hline $\begin{array}{l}\text { Pornography craving (Range } \\
0-60), M(S D)\end{array}$ & $42.9(16.2)$ & $50.5(14.7)$ & $46.9(16.1)$ & $\begin{array}{c}F(2,120)=0.04 \\
P=0.109\end{array}$ \\
\hline $\begin{array}{l}\text { Pornography avoidance self- } \\
\text { efficacy (Range 0-100), } \\
M(S D)\end{array}$ & $54.1(20.1)$ & $49.1(14.5)$ & $53.1(18.8)$ & $\begin{array}{c}F(2,120)=0.85 \\
P=0.432\end{array}$ \\
\hline $\begin{array}{l}\text { Sex mindset, (Range 5-30), } \\
\quad M(S D)\end{array}$ & $13.5(5.1)$ & $12.5(5.5)$ & $13.0(5.1)$ & $\begin{array}{c}F(2,120)=0.32 \\
P=0.726\end{array}$ \\
\hline $\begin{array}{l}\text { Sexual satisfaction, } \\
\quad \text { (Range } 0-4), M(S D)\end{array}$ & $2.3(1.4)$ & $1.9(1.4)$ & $2.1(1.2)$ & $\begin{array}{c}F(2,77)=0.58 \\
P=0.564\end{array}$ \\
\hline $\begin{array}{l}\text { Satisfaction with life, } \\
\quad \text { (Range 5-35), } M(S D)\end{array}$ & $18.5(7.6)$ & $17.2(7.0)$ & $20.7(7.5)$ & $\begin{array}{c}F(2,120)=2.36 \\
P=0.098\end{array}$ \\
\hline $\begin{array}{l}\text { Self-report adult } A D H D^{\mathrm{b}} \\
\quad \text { (Range } 0-24), M(S D)\end{array}$ & $11.2(4.3)$ & $12.7(3.7)$ & $12.0(4.5)$ & $\begin{array}{c}F(2,120)=1.30 \\
P=0.276\end{array}$ \\
\hline \multirow[t]{2}{*}{$\begin{array}{r}\text { Alcohol-related problems, } \\
\text { (Range 0-45), } M(S D)\end{array}$} & $3.5(7.6)$ & $2.8(6.3)$ & $1.6(3.1)$ & $\begin{array}{c}F(2,120)=1.13 \\
P=0.328\end{array}$ \\
\hline & $15.9(11.7)$ & $22.1(13.3)$ & $17.5(12.1)$ & \\
\hline
\end{tabular}


Table A1. Continued

\begin{tabular}{|c|c|c|c|c|}
\hline & $\begin{array}{l}\text { Did not complete any } \\
\text { moules }(n=41)\end{array}$ & $\begin{array}{l}\text { Completed only one } \\
\text { module }(n=37)\end{array}$ & $\begin{array}{l}\text { Completed more than } \\
\text { one module }(n=45)\end{array}$ & $\begin{array}{l}\text { Statistical Analysis (Chi- } \\
\text { Square Test, ANOVA) }\end{array}$ \\
\hline $\begin{array}{l}\text { Psychiatric symptoms } \\
\quad \text { (depressive, anxiety, and } \\
\text { somatization symptoms) } \\
\text { (Range } 0-72), M(S D)\end{array}$ & & & & $\begin{array}{c}F(2,120)=2.59 \\
P=0.079\end{array}$ \\
\hline $\begin{array}{l}\text { Positive emotions, } \\
\quad \text { (Range } 0-20), M(S D)\end{array}$ & $14.6(3.6)$ & $14.9(3.8)$ & $15.5(3.2)$ & $\begin{array}{c}F(2,120)=0.68 \\
P=0.508\end{array}$ \\
\hline $\begin{array}{l}\text { Negative emotions, } \\
\quad \text { (Range } 0-20), M(S D)\end{array}$ & $17.5(3.9)$ & $17.2(4.5)$ & $17.1(3.8)$ & $\begin{array}{c}F(2,120)=0.15 \\
P=0.864\end{array}$ \\
\hline \multicolumn{5}{|l|}{ Cannabis use,$n(\%)$} \\
\hline Never & $23(56.1)$ & $26(70.3)$ & $35(77.8)$ & $\begin{aligned} \chi^{2}(4, N & =123)=5.52 \\
P & =0.063\end{aligned}$ \\
\hline Once or twice & $8(19.5)$ & $5(16.2)$ & $6(13.3)$ & \\
\hline Monthly & $2(4.9)$ & $2(5.4)$ & $0(0)$ & \\
\hline Weekly & $3(7.3)$ & $3(8.1)$ & $3(6.7)$ & \\
\hline Daily or almost daily & $5(12.2)$ & $0(0.0)$ & $1(2.2)$ & \\
\hline \multicolumn{5}{|c|}{ Prescription stimulants use ${ }^{c}, n(\%)$} \\
\hline Never & $35(85.4)$ & $30(81.1)$ & $39(86.7)$ & $\begin{aligned} \chi^{2}(4, N & =123)=0.67 \\
P & =0.716\end{aligned}$ \\
\hline Once or twice & $0(0.0)$ & $0(0.0)$ & $2(4.4)$ & \\
\hline Monthly & $0(0.0$ & $0(0.0)$ & $0(0.0)$ & \\
\hline Weekly & $1(2.4)$ & $0(0.0)$ & $0(0.0)$ & \\
\hline Daily or almost daily & $5(12.2)$ & $7(18.9)$ & $4(8.9)$ & \\
\hline
\end{tabular}

Note. ${ }^{\mathrm{a}}$ Less than 5 participants in each unlisted country, ${ }^{\mathrm{b}} \mathrm{ADHD}$ : attention deficit hyperactivity disorder, ${ }^{\mathrm{c}}$ Previous three months; the two most commonly used substances (i.e., cannabis and prescription stimulants) are included in table. $M=$ mean, $S D=$ standard deviation, $N A=$ not applicable. 